\title{
EL LEGADO DEL POSITIVISMO LÓGICO, 50 AÑOS DESPUÉS. LA AUTOINMUNIDAD HIPERCRÍTICA DEL NEODUALISMO POSTANALÍTICO. (A TRAVÉS DE VON WRIGHT Y APEL)
}

\author{
THE LEGACY OF LOGIC POSITIVISM, 50 YEAR AFTER. THE \\ HYPERCRITICAL AUTOIMMUNITY OF POST-ANALYTICAL \\ "NEW DUALISM". (ACROSS VON WRIGHT AND APEL)
}

\author{
Carlos Ortiz de Landázuri ${ }^{1}$ \\ Universidad de Navarra
}

Recibido: 15/ 4/ 16

Aceptado: 30/ 9/ 16

\begin{abstract}
Resumen: Wright y Apel pusieron de manifiesto como el positivismo lógico de Russell y el primer Wittgenstein tuvo en la estricta separación leibniziana entre lo analítico y lo sintético una de sus muchas señas de identidad. Pero a su vez, ambos autores señalan cómo Wittgenstein y Popper se acabarían reprochando que sus respectivas propuestas acerca de la experiencia y del lenguaje científico adolecieran de una condición de tipo oracular o simplemente ficcional, respectivamente, con posturas cada vez más irreconciliables. Sin embargo las posteriores corrientes del positivismo lógico, según Wright y Apel, acabarían defendiendo un neodualismo postanalítico donde se sugeriría una posible integración entre ambas propuestas, defendiendo una posible complementariedad entre la explicación y la comprensión, aunque desde planteamientos muy distintos.
\end{abstract}

Palabras clave: analítico, dualismo, lenguaje, ciencia, método.

1. (cortiz@unav.es) Catedrático de Instituto de Enseñanzas Medias desde 1976 (jubilado). Profesor visitante de la Universidad de Navarra en la asignatura de Historia y Metodología de la Ciencia desde el curso 1976/77 (Jubilado). Tesis doctoral en 1885 en la Universidad de Navarra sobre 'Acción y método en la transformación de la filosofía de Karl-Otto Apel'. Diversos artículos en diversas revistas, como Anuario Filosófico, Contrastes o Thémata sobre Apel, von Wright, Wittgenstein, Popper, Heidegger. Numerosas reseñas de libros en Anuario Filosófico, Teorema, Theoria, Educación y sociedad, Acta Philosófica, Diálogo Filosófico, Paideia. Últimas publicaciones: Ortiz de Landázuri, C.; 'La segunda recepción de la 'Mathesis universalis' leibniziana a finales del siglo XX. A través del proyecto “New Foundation” de Barwise-Moss, y de la lógica deóntica de M. Sánchez Mazas', Sánchez Rodríguez, M.; Rodero Cilleros, S. (eds.); "Leibniz en la filosofía y la ciencia modernas", Comares, Granada, 2010, 467-483 pp. (Congreso Internacional sobre Leibniz, Universidad de Granada, 2007). Ortiz de Landázuri, C.; 'El antifundamentalismo radical del neodualismo postanalítico. A través de von Wright y Apel', Contrastes, Vol XX, nº 1, 2015, pp. 27-43. 


\begin{abstract}
Wright and Apel revealed as the logical positivism of Russe11 and the first Wittgenstein had in Leibniz's strict separation between analytic and synthetic one of his many hallmarks. But in turn, both authors point out how Wittgenstein and Popper would end reproaching their respective proposals on the scientific language suffered from a condition of oracular type or just fictional, respectively, with increasingly irreconcilable positions. However current post of logical positivism, according to Wright and Apel, would end up defending a post-analytic dualism where possible integration between the two proposals suggest, advocating a possible complementarity between explanation and understanding, although from position very different.
\end{abstract}

Key words: analytic, dualism, language, science, method.

\title{
1. Wright, 1971: Apel, 1979: el debate entre Wittgenstein y Popper, 50 años después
}

Von Wright reconstruyó en Explicación y comprensión (1971) - EU-2, el debate metodológico que durante los 50 años anteriores y los 50 siguiente posteriores habría tenido lugar entre los defensores de una vuelta a las propuestas ya sea del primer Wittgenstein del “Tractatus" (1923) - $\mathrm{T}^{3}$-o del Popper de la Lógica de la investigación científica (1933) - $\mathrm{LF}^{4}$-. Por su parte, Karl Otto Apel revisó los planteamientos de von Wright, en La controversia explicación y comprensión (1979) -EVKTPS ${ }^{5}$ - prolongando y corrigiendo algunos de sus proyectos. Consideró que todas estas corrientes de pensamiento acabaron convergiendo hacia lo que ahora se denomina un "nuevo dualismo" post-analítico. Se trató en cualquier caso de un debate en el que se siguió aceptando el dualismo analítico-sintético leibniziano que había caracterizado al positivismo lógico en su primera época. Sin embargo estas posteriores corrientes le otorgaron un nuevo sentido explicativo-comprensivo que estaba basado en unos presupuestos más complejos. En efecto, se comprobó como el segundo Wittgenstein y el propio Popper acabaron considerando excesivamente simplista el optimismo inductivo y

2. Wright, G. H. von; Explanation and Understanding, Cornell University, Ithaca, 1971; Explicación y comprensión, Alianza, Madrid, 1987.

3. Wittgenstein, Ludwig; Tractatus logico-philosophicus; Valdés Villenueva, L. M. (ed); Tecnos, Madrid, 2003.

4. Popper, K. R.; Logik der Forschung, J. C. B. Mohr (Paul Siebeck), Tübingen, 1934 (1²), 1989.

5. Apel, K. O.; Die Erklären:Verstehen-Kontroverse in transzendentalpragmatischer SichtEVKTPS-, Suhrkamp, Frankfurt, 1979.

Thémata. Revista de Filosofía №55 (2017) pp.: 83-130. 


\section{El legado del positivismo lógico, 50 años después. \\ La autoinmunidad hipercrítica del neodualismo postanalítico}

el dogmatismo axiomático de aquel primer positivismo lógico, o el simple falibilismo hipotético, proponiendo en su lugar un planteamiento explicativo-comprensivo más complejo ${ }^{6}$.

Por eso, el segundo Wittgentein habría defendido una posible ampliación de su anterior uso analítico de las proposiciones científicas donde también pudiera caber una posible explicación pragmático-inductiva de los hechos de la experiencia Es decir, una ampliación del uso antes otorgado a sus propios principio analíticos a fin de que también pudiera tener cabida cualquier forma de explicación que a su vez estuviera basada en el seguimiento de un principio de la regla del modus ponens. Por su parte Popper también habría defendido una posible ampliación del anterior uso otorgado a lo sintético a fin de que también pudiera tener cabida un posible proceso de comprensión hipotético-deductiva de los presupuestos implícitos en los hechos de la experiencia. Es decir, una posible ampliación de sus propios principios analíticos y sintéticos mediante los que se pudiera garantizar la autoinmunidad de sus propios presupuestos heurísticos explicativos y comprensivos, ya fuera mediante el seguimiento de una regla del modus tollens o del modus ponens, así como mediante la aplicación de una regla de la buena consecuencia lógica o de un principio de no contradicción. Sólo así ciertos principios metodológicos podrían seguir siendo considerados como principios absolutamente válidos frente a cualquier tipo de ciencia, a pesar de no poder aportar una prueba absolutamente fehaciente de su validez intrínseca ${ }^{7}$.

De todos modos el debate surgió cuando el segundo Wittgenstein criticó el carácter ficcional de la pretendida autoinmunidad falibilista de este tipo de presupuestos comprensivos que, como el modus tollens, Popper consideró irrenunciables. O cuando a su vez, Popper denunció a su vez el dogmatismo futurista oracular subyacente a de estas propuestas explicativas que el primer Wittgenstein consideró irrenunciables, a pesar de justificarse simplemente en nombre del modus ponens. En efecto, según Popper, el primer Wittgenstein habría seguido defendiendo una pluralidad de procedimientos inductivos o simplemente hipotético-confirmadores cuya comprensión se legitimaba en virtud de un futurismo oracular aún más adivinatorio. Pero, por su parte, según Wittgenstein, Popper habría seguido defendiendo el carácter ficcional de la autoinmunidad falibilista con la que el positivismo lógico habría pretendido seguir justificando

6. Ortiz de Landázuri, C.; 'La autodestrucción de la crítica del sentido en Wittgenstein y Heidegger. (A través de Karl-Otto Apel)', Anuario Filosófico, 2000/3, p. 833-859.

7. Munz, P.; Beyond Wittgenstein's Poker: New Light on Popper and Wittgenstein, Ashgate, London, 2004.

Thémata. Revista de Filosofía N55 (2017) pp.: 83-130. 
determinados presupuestos comprensivos considerados irrenunciables, a pesar de seguir justificándolos de un modo meramente inductivo ${ }^{8}$.

Máxime cuando von Wright y posteriormente Apel hagan notar como las corrientes más actuales del llamado "nuevo dualismo" post-analítico habrían llevado a cabo una compleja reconstrucción del subsiguiente proceso de convergencia creciente que se habría producido entre ambos proyectos programáticos. En efecto, en la medida que tanto las propuestas de Wittgenstein como las de Popper mantienen una dependencia interna recíproca entre sus respectivos procesos de compresión y explicación, tampoco pueden prescindir de las respectivas posiciones contrarias. Es decir, von Wright y Apel habrían comprobado cómo la inicial aceptación de la inducción explicativa por parte de positivismo lógico del primer Wittgenstein tampoco pudo evitar una futura dependencia respecto de una posible falsación o refutación conceptual de los respectivos fracasos de una determinada comprensión de la respectiva hipótesis. Ni tampoco el principio de refutación de Popper pudo eludir una hipotética subordinación respecto de la inevitable comprensión de nuevo juego de lenguaje, desde el que a su vez se formalizan los hechos de la experiencia. De hecho ninguna postura pudo prescindir de su contraria, si verdaderamente pretenden progresar en la investigación científica. Y aún más, cuando von Wright y Apel hagan notar como los procesos explicativos y comprensivos se deben remitir a unos similares presupuestos transcendentales en sí mismos incondicionados, si pretenden continuar garantizando la ilimitada mejora que siempre cabe en este tipo de procesos ${ }^{9}$.

\section{1.a. El legado del positivismo lógico, 50 años después}

En efecto, según von Wright y Apel las mas recientes corrientes del "nuevo dualismo" post-analítico, seguidoras de Russell y del primer Wittgenstein, habrían tratado de seguir justificando los ideales del positivismo lógico, aunque siguiendo una estrategia explicativo-comprensiva distinta. Por ejemplo, habrían compartido la posible comprensión recíproca del ideal semiótico de un lenguaje perfecto simultáneamente compartido, a pesar de seguir careciendo de un argumento explicativo adecuado para justificar este mismo supuesto. De todos modos se reconoce cómo el primer Wittgenstein habría acertado plenamente al tratar de erradicar

8. Stern, D. G.; Szabados, B.; Wittgenstein Reads Weininger, Cambridge University, Cambridge, 2004.

9. Landesmann, Ch.; "The New Dualism in the Philosophy of the Mind", Rev. of Metaph, 19, 1965/66, 329-349 pp.

Thémata. Revista de Filosofía N 55 (2017) pp.: 83-130. 


\section{El legado del positivismo lógico, 50 años después. \\ La autoinmunidad hipercrítica del neodualismo postanalítico}

un posible mal uso del lenguaje, aunque para ello tuviera que explicar este primer paso en virtud de razones simplemente pragmáticas. O como Popper habría acertado plenamente al denunciar el carácter no científico de todo proceso de comprensión de supuestos que haga un uso abusivo del principio de inducción, como ocurrió con numerosas proposiciones de los saberes pseudocietíficos y similares ${ }^{10}$.

Pero a pesar de este acierto indudable, von Wright y Apel tampoco pudieron evitar la aparición de la llamada paradoja del irrenunciable legado dejado por el positivismo lógico: en efecto, después de casi 50 años de propuestas neo-positivistas y a pesar de los numerosos fracasos cosechados, todavía habría que seguir reconociendo que no se había logrado un modelo alternativo compartido. En este sentido se debería seguir asumiendo como un simple ideal aún por lograr la aceptación experimental compartida de un determinado tipo de supuestos explicativos, o el mantenimiento de determinadas presupuestos comprensivos autoinmunes a su propia falsación o refutación, como ahora seguirá ocurriendo en el llamado nuevo dualismo post-analítico, cuando en principio se exigía lo contrario. De ahí que también ahora Wright y Apel señalen los siguientes pasos que tuvieron que admitir los defensores del llamado "nuevo dualismo" postanalítico ${ }^{11}$.

Primero: se debe reconocer explícitamente, una vez desechada la validez del procedimiento inductivo, la carencia de un procedimiento heurístico explicativo proporcionado que le hubiera permitido garantizar al primer Wittgenstein la efectiva elaboración de un lenguaje ideal que lograra la efectiva erradicación del mal uso del lenguaje. De hecho se considera cómo claramente insuficiente la pretensión de resolver este problema recurriendo de un modo meramente instrumental a un conjunto de dogmatismos axiomáticos totalmente injustificados, cuando lo único que se consigue de este modo fue multiplicar el número de los llamados problemas de fundamentación, generando un escepticismo aún mayor ${ }^{12}$.

Segundo: el "nuevo dualismo" siguió justificando la necesidad de seguir manteniendo un criterio de demarcación explicativo-comprensivo en cierto modo similar a la propuesta analítico-sintética propuesta por Russell y el primer Wittgenstein, a pesar de los numerosos fracasos cosechados al respecto. De ahí que hoy día se debe volver a proponer deliberadamente un

10. Cf. Lewis, P. (ed); Wittgenstein, Aesthetics and Philosophy, Ashgate, Hampshire, 2002.

11. Ortiz de Landázuri, C.; 'La doble génesis semiótica y heurística del neodualismo postanalítico. (A través del primer Wittgenstein y Popper, según von Wright y Apel)', Contrastes, Málaga, 2011.

12. Sobre el paralelismo entre las tesis del primer Wittgenstein y de K. Popper, cf. Apel, K. O.; Transformation der Philosophie, Suhrkamp, Frankfurt, 1973.

Thémata. Revista de Filosofía Nº55 (2017) pp.: 83-130. 
doble dogmatismo explicativo-comprensivo de carácter pseudo-inductivo y a la vez pseudo-axiomático, a sabiendas de que de no hacerlo se trataría de una propuesta insostenible desde un punto de vista estrictamente metodológico. En cualquier caso el "nuevo dualismo", según Wright y Apel, tuvo que reconocer la necesidad de este doble proceso explicativo-comprensivo en virtud de la denuncia del anterior dogmatismo inductivo y de una pretendida autoinmunidad falibilista. Sólo así sería posible erradicar, o al menos desactivar, un efectivo mal uso intencionado del lenguaje o de la propia metafísica, al menos desde un punto de vista pragmático ${ }^{13}$.

Tercero: el "nuevo dualismo" post-analítico tuvo que reconocer la necesidad de posponer ilimitadamente la resolución explicativo-comprensiva de esta anterior doble paradoja u oximoron, que ahora se establece entre lo analítico y lo sintético, dada la intrínseca dependencia que se establece entre ambos problemas. Sólo así habría sido posible dar un paso hacia otra estrategia heurística menos rigurosa, pero más resolutiva a largo plazo, a saber: dejar que la academia se vaya convenciendo del carácter verdaderamente irrenunciable de este tipo de propuestas en virtud de los propios resultados pragmáticos alcanzados a largo y sobre todo corto plazo, sin que haya ninguna otra estrategia posible a la que se pueda recurrir ${ }^{14}$.

En efecto, según von Wright y Apel, en la misma medida que este nuevo proyecto programático explicativo-comprensivo se justifica en virtud de razones estrictamente pragmáticas, o si se prefiere, estrictamente pragmático-transcendentales, se debe reconocer como el nuevo proyecto explicativo-comprensivo se acabó imponiendo más por una vía prácticas que teórica. En cualquier caso, ya se siga una estrategia teórica o práctica, se tendrá que reconocer la verdadera necesidad de estos presupuestos explicativos-comprensivos, en razón de las indudables ventajas a corto y largo plazo que pueden deparar este tipo de proyectos programáticos en un ámbito heurístico. Por eso se deberá seguir confiando en que la historia de la ciencia y de la propia humanidad termine dando la razón a unos planteamientos semióticos y metodológicos que todavía hoy día resultan carentes de una justificación racional adecuada. En este sentido sólo el paso del tiempo y la propia historia tendrán la última palabra al respecto, aunque ello exija tener que otorgarles un nuevo voto de confianza ${ }^{15}$

Además, las corrientes actuales de "nuevo dualismo" post-analitico acabarían confirmando sus anteriores sospechas cuando comprobaron

13. Wuchterl, K.; Handbuch der analytischen Philosophie und Grundlagenforschung. Von Frege zu Wittgenstein, Haupt, Bern, 2002.

14. Baker, G. P.; Hacker, P. M. S.; Wittgenstein Meaning and Understanding. Essays on the Philosophical Investigations I, Blackwell, Oxford, 2004.

15. En cualquier caso fue fácil de comprobar este profundo carácter dogmático del "Trac-

Thémata. Revista de Filosofía N55 (2017) pp.: 83-130. 


\section{El legado del positivismo lógico, 50 años después. \\ La autoinmunidad hipercrítica del neodualismo postanalítico}

con satisfacción el creciente proceso de progresiva convergencia experimentado por la inicial estrategia positivista lógica y esta segunda alternativa metodológica popperiana de tipo falsacionista. Especialmente cuando se comprueba cómo la inicial defensa de las propuestas analítico-sintéticas del positivismo lógico de Russell y del primer Wittgenstein de hecho compartían un gran número de objetivos con las propuestas explicativo-comprensivas popperianas, a pesar de la inicial contraposición existente entre ambas. De hecho, habría sido Karl R. Popper quién habría hecho notar la dependencia que el modelo explicativo del positivismo lógico del primer Wittgenstein seguía manteniendo respecto de la previa aceptación de un doble proceso de creciente falsacionismo inductivista. De igual modo que Wittgenstein hizo notar como una correcta comprensión del racionalismo crítico popperiano dependía a su vez del previo reconocimiento de la "autoinmunidad" falibista respecto determinados presupuestos considerados hipotéticamente universales, aunque en ambos casos este tipo de supuestos no se quisiera reconocer. De hecho, por un lado, el primer Wittgenstein habría aplicado a las explicaciones heurísticas una previa metodología pseudo-inductiva, así como una lógica formal pseudo-axiomática, que resultaban a su vez claramente insuficientes para alcanzar los objetivos enciclopédicos tan ambiciosos que en su caso se proponían. Por su parte, Popper habría exigido la aplicación a todo proceso de comprensión de presupuestos un falibilismo generalizado que en la práctica hacía inviable el proyecto programático de explicaciones cientifistas que se proponía acometer ${ }^{16}$.

En cualquier caso los seguidores de Popper habrían pretendido abordar el problema de la comprensión de la intersubjetividad del conocimiento y del correspondiente lenguaje científico mediante una perspectiva heurística falsacionista o refutadora que fuera verdaderamente autoinmune ante cualquier posible oponente. Además, se pretendía así denunciar el presunto dogmatismo inductivo de los modelos explicativos propuestos por el primer Wittgenstein, sin poder aportar razones proporcionadas al respecto. Por su parte, los seguidores de Wittgenstein habrían abordado la explicación inductiva del conocimiento científico desde unos planteamientos aún más empiristas y fisicalistas, denunciando el presunto raciona-

tatus" cuando el primer Wittgenstein afirma: >"La realidad tiene que quedar fijada por la proposición en orden al sí y al no. (...) La proposición construye un mundo con ayuda de un armazón lógico, y por ello, también puede verse en ella como se comporta todo lo lógico, si es verdadera. (...) Comprender una proposición quiere decir saber lo que es el caso si es verdadera (...) Se la comprende si se comprenden sus partes integrantes" $<$. Wittgenstein, L.; TLP, 4.023, 4.024; Ostrow, M. B.; Wittgenstein's Tractatus. A dialectical Interpretation, Cambridge University, Cambridge, 2002.

16. Mulhgall, S.; Wittgenstein's Private Language. Grammar, Nonsense, and Imagination in Philosophical Investigations, \&\& 243-315, Oxford University, Oxford, 2006.

Thémata. Revista de Filosofía Nº55 (2017) pp.: 83-130. 
lismo crítico de las propuestas de Popper. En efecto, si se pretende eludir la atribución al lenguaje científico de un origen convencional en sí mismo dogmático, como ahora seguía ocurriendo en el primer Wittgenstein, se acabaría haciendo absolutamente necesaria recurrir a la propuesta del segundo Wittgenstein ${ }^{17}$.

Se pasaría así de marcarse un objetivo explicativo inductivo a otro de tipo comprensivo o hipotético-deductivo muy diferente, a saber: tener que invertir de un modo hipercrítico el modo de justificar las iniciales propuestas dogmáticas positivistas del primer Wittgenstein, aunque para comprender estos mismos procesos hubiera que recurrir a los supuestos autoinmunes falibilistas de Popper. Pero si se pretende evitar justificar el origen del lenguaje científico en virtud de un inductitivismo meramente oracular, al modo de Wittgenstein, o de un decisionismo meramente ficcional, al modo de Popper, no se tendrá más remedio que recurrir a un axiomática cada vez más dogmática o a un falibilismo cada vez más radicalizado y escéptico, a pesar que de ambos modos se impide cualquier posible avance de la ciencia. De hecho el "nuevo dualismo" post-analítico tendría que otorgar a la génesis del lenguaje y de la propia experiencia, o bien un claro sentido inductivo-axiomático o bien un simple planteamiento hipotético-deductivo cada vez más falibilista. En ambos casos el "nuevo dualismo" tuvo que formular sus propuestas tras un ropaje metodológica y semióticamente pluralista, aunque con pretensiones claramente autoinmunes y enciclopédicas, como realmente acabó sucediendo en el segundo Wittgenstein, o en el propio Popper. Sin embargo en ambos caso se seguían manteniendo los mismos ideales dogmáticos del positivismo lógico, aunque se siguieran diversas estrategias par lograrlo ${ }^{18}$. Veámoslo.

\section{1.b. La paradójica convergencia explicativo-comprensiva entre Wittgenstein y Popper}

A este respecto, según von Wright y Apel, la "lógica falsacionista" de Popper también habría tratado de invertir a este respecto el anterior carácter inductivo-axiomático de la génesis logicista del lenguaje en Russell y el primer Wittgenstein, aunque ahora se siguieran unos procedimientos explicativo-comprensivos muy distintos. En efecto, en vez de recu-

17. Wuchterl, K.; Handbuch der analytischen Philosophie und Grundlagenforschung. Von Frege zu Wittgenstein, Haupt, Bern, 2002.

18. Ortiz de Landázuri, C.; "El antifundamentalismo radical del neodualismo postanalítico. A través de von Wright y Apel. The radical anti-fundamentalism of post-analytics neodualism. Across von Wright and Apel”, Contrastes, Málaga, 2016, 21-45 pp.

Thémata. Revista de Filosofía N 55 (2017) pp.: 83-130. 


\section{El legado del positivismo lógico, 50 años después. \\ La autoinmunidad hipercrítica del neodualismo postanalítico}

rrir a la semiótica explicativa del lenguaje científico, como en el segundo Wittgenstein, Popper habría recurrido a la metodología comprensiva del saber científico, con resultados en gran parte convergentes. En este sentido el segundo Wittgentein habría recurrido a un principio de proliferación de los juegos del lenguaje, que cuestiona su tesis inicial de la pretendida existencia de un solo lenguaje ideal perfecto válido para las explicaciones de todas las ciencias. En cambio Popper habría tratado de justificar el correspondiente proyecto programático comprensivo de la lógica de la justificación científica en nombre de un método hipotético-deductivo de carácter estrictamente refutador o falibilista. De este modo Wittgenstein habría fomentado un inductivismo con la única pretensión de explicar las consecuencias válidas de las teorías científicas. En cambio, Popper habría fomentado un decisionismo crítico que sólo perseguiría la comprensión meramente hipotética de determinados presupuestos que podrían ser verificados o refutados en la experiencia ${ }^{19}$.

Sin embargo para que ambas propuestas pudieran ser provisionalmente viables se les debería seguir asignando inicialmente una naturaleza inductiva o hipotética igualmente dogmática. Hasta el punto que habría que justificar este inductivismo o este convencionalismo o decisionismo crítico en virtud del valor explicativo meramente inductivo otorgado a las verificaciones científicas o en virtud del valor meramente hipotético otorgado a la comprensión heurística de las leyes y teorías científicas. Hasta el punto que también las convenciones semióticas que regulan el propio lenguaje científico deberían admitir una única exigencia: la necesidad de fomentar una aplicación a una base empírica lo más concreta posible, o bien garantizar la posible sustitución de la hipótesis inicial refutada por otra mejor aún más universal. Sólo en el caso de que se dispusiera demarcar de un modo más preciso la base empírica disponible o de disponer de una hipótesis cada vez más universal, sólo entonces se podría iniciar un proceso de efectiva confirmación de una explicación experimental o de refutación de la comprensión alcanzada de una determinada hipótesis. Pero en el caso contrario se debería desistir de hacer este tipo de propuestas por fomentar una actitud en sí misma regresiva ${ }^{20}$.

Evidentemente von Wright y Apel constataron como a lo largo de los 50 años últimos se acabaría produciendo un fuerte proceso de conver-

19. F. Kuhn, Ein anderes Bild des Pragmatismus, Vittorio Klostermann, Frankfurt, 1996.

20. A este respecto Popper afirmó: > El criterio de demarcación inherente a la lógica inductiva - esto es, el dogma positivista del significado o sentido - equivale a exigir que todos los enunciados de la ciencia empírica (o, todos los enunciados con sentido) sean susceptibles de una decisión definitiva con respecto a su verdad o falsedad; podemos decir que tienen que ser "decidibles de modo concluyente". Esto quiere decir que han de tener una forma tal que sea lógicamente posible tanto verificarlos como falsarlos (...). Ahora bien, en mi opinión, no existe

Thémata. Revista de Filosofía N55 (2017) pp.: 83-130. 
gencia entre ) la teoría de los juegos del lenguaje del segundo Wittgenstein, por un lado, y de la lógica racionalista crítica de la refutación de Popper, por otro, a pesar de haber defendido inicialmente proyectos programáticos totalmente enfrentados. Máxime cuando se comprobó como la mera justificación inductiva de los resultados de la ciencia respondía a un modelo de explicación causal de cobertura legal muy preciso. En cambio la justificación falsacionista acerca del origen de las leyes y teorías científicas respondía más bien a un modelo comprensivo de presuposiciones previas. Además, la justificación del propio lenguaje semiótico requería la justificación previa de un doble proceso convencionalista que, ya se conciba de un modo dogmático, o alternativamente hipotético-deductivo, tampoco mantienen unas diferencias programáticas tan opuestas como inicialmente podría parecer. En realidad, y por mucho que ninguno de ambos lo quisiera reconocer, se habían formulado recíprocamente objeciones bastantes similares. Por un lado, Wittgenstein había denunciado que Popper justificara los procesos de comprensión de las hipótesis de un modo muy vulgar en virtud de simples propuestas provisionales y de meras deducciones convencionalistas. Pero por su parte Popper había objetado al primer Wittgenstein que siguiera recurriendo a simples inducciones generalizadoras de carácter muy parcial, o de servirse de una axiomática terapéutica cuyo valor último se sigue legitimando de un modo simplemente pragmático a largo plazo, sin lograr justificarse verdaderamente por sí misma ${ }^{21}$.

Pero a pesar de estas divergencias y convergencias entre Wittgenstein y Popper, sin embargo el resultado final en ambos casos acabó resultando bastante similar. La defensa de un "nuevo dualismo" explicativo-comprensivo donde en cada caso se pone el acento en uno de loe elementos de la mencionada relación. De hecho en ambas estrategias heurísticas sólo se persigue la explicación confirmadora o la comprensión refutable de unas determinadas propuestas científicas iniciales. Por su parte, a la vez que se trata de garantizar un uso cada más correcto del lenguaje científico, a pesar de que en cada caso también se siguieran unas estrategias dispares, pero complementarias. Se genera así un proceso de convergencia que, según von Wright y Apel, se incrementaría aún más cuando en las nuevas tendencias post-analíticas de los "nuevos dualistas" se analicen más específicamente los modelos de cobertura legal subyacentes a dichos procesos de explicación y comprensión. Especialmente cuando se compruebe que se trata de dos alternativas semiótica o metodológicas en el fondo comple-

nada que pueda llamarse inducción"<. Popper, K.; LF, p. 14; LSD, p. 40; LIC, p. 39. Cf. Ortiz de Landázuri, C.; 'La probabilidad inductiva hoy: ¿Carnap, Popper o Bayes?', Encuentro de lógica y filosofía de la ciencia. Rudolf Carnap y Hans Reichenbach in Memoriam, Universidad Complutense, Madrid 13-15 Noviembre de 1991, 395-401 págs.

21. Russell, B.; Toward the "Principles of Mathematics", 1900-02, Routledge, London, 1993.

Thémata. Revista de Filosofía N55 (2017) pp.: 83-130. 


\section{El legado del positivismo lógico, 50 años después. \\ La autoinmunidad hipercrítica del neodualismo postanalítico}

mentarias. De hecho las "nuevas corrientes" analíticas acabarían propugnado con una gran tenacidad una vuelta a los planteamientos positivistas lógicos de Russell y del primer Wittgenstein, o a las estrategias racionalistas críticas de Popper. Se vieron sus propuestas como complementarias, sin querer establecer ya ningún tipo de contraposición entre ellas. De hecho el "nuevo dualismo" acabaría viendo en la lógica de la refutación de Popper un complemento necesario aún más sofisticado de las propuestas analíticas del positivismo lógico inicial. Además, se trataría de compensar de este modo algunas lagunas e insuficiencias semióticas presentes en la metodología dogmática de Russell y del primer Wittgenstein, así como en racionalismo-crítico post-popperiano ${ }^{22}$.

\section{1.c. El dilema heurístico explicación-comprensión entre Wi- ttgenstein y Popper.}

Pero, a pesar de generar estos procesos de convergencia cada vez más acusados, según von Wright y Apel, tampoco desaparecieron totalmente las profundas diferencias que anteriormente habían abierto un abismo intransitable entre los respectivos proyectos programáticos positivistas-lógicos del primer Wittgenstein y racionistas críticos de Popper ${ }^{23}$.

De hecho el proyecto programático positivista lógico defendía un modelo explicativo, que estaba basado en un fuerte dogmatismo inductivo y axiomático muy persistente. Además, se trataba de un modelo explicativo que volvía una y otra vez a reaparecer de un modo muy hipercrítico, por mucho que a corto plazo muchas de sus tesis pudieran ser refutadas mediante un "experimento crucial". Máxime cuando tampoco se pudieron ver materializadas su irrenunciable expectativa de alcanzar el prometido avance efectivo hacia el logro de un lenguaje ideal perfecto, como en principio hubiera sido de esperar. Es más, se seguía haciendo presente un persistente mal uso del lenguaje por parte de la ciencia que a su vez sólo servía para reafirmarse aún más en la necesidad de volver a justificar un uso al menos instrumental de aquellos mismos dogmatismos inductivos

22. McGinn, M.; Elucidating the 'Tractatus'. Wittgenstein's Early Philosophy of Logic and Language, Clarendon, Oxford University, Oxford, 2006.

23. Ter-Hark, M.; Popper, Otto Selz and the Rise of Evolutionary Epistemology, Cambridge University, Cambridge, 2004.

Thémata. Revista de Filosofía N55 (2017) pp.: 83-130. 
igualmente denostados, sin llegar tampoco a alcanzar una adecuada justificación teórica ${ }^{24}$.

Por su parte, la lógica de la investigación científica falsacionista popperiana cada vez más se enrocó en la justificación de una presunta autoinmunidad metodológica falsacionista aún más radicalizada. En efecto, en la medida que alguna de sus propuestas podían acabar siendo refutadas siempre se veía obligada a volver a justificar un modelo comprensivo similar que les permitiera salir incluso más reforzada de sus propias refutaciones, al igual que sucedía con las demás teorías. Hasta el punto que la persistente refutación de las diversas teorías sólo acabó sirviendo para reforzar aún más la aparición de una "nueva" forma de autoinmunidad falibilista, salvo que se quisiera fomentar una falsacionismo aún más radicalizado. Hasta el punto que algunos post-popperianos exigieron incluso admitir la posible refutación de los primeros principios de la razón natural, incluido el principio de no contradicción, como acabó ocurriendo en Feyerabend o Bartley. Es decir, la necesidad absoluta de que la teoría refutada pudiera ser sustituida por otra aún mejor verificada, sin admitir la posibilidad de que antes o después un hecho pudiera quedar sin justificación alguna. Al menos así siguió siendo reivindicado tenazmente por el correspondiente proyecto programático del llamado convencionalismo o decisionismo crítico, cuando en buena ley podría haberles llevado a la conclusión contraria ${ }^{25}$.

Evidentemente, según von Wright y Apel, los desarrollos del "nuevo dualismo" post-analítico durante los últimos 50 años han generado un debate entre la explicación y la comprensión que no han dejado a nadie indiferentes. Sin duda el proceso comenzó por los propios analíticos, o más bien post-analíticos, posteriores al segundo Wittgenstein, que a estas alturas también se reconocían postpoperianos. Hasta el punto que muchos de ellos aún siguieron manteniendo la añoranza de pretender volver a defender las propuestas iniciales del primer Wittgenstein, siempre que las propuestas iniciales del positivismo lógico sólo se afirmasen como un presupuesto implícito necesario del propio principio de refutación. A este respecto se habría producido, según von Wright, un lento, pero inexorable deslizamiento del debate estrictamente metodológico a otro propiamente semiótico, o a la inversa, según el punto de partida del autor considerado. Es decir, un tránsito desde un debate acerca de los métodos explicativos a otro acerca de los presupuestos comprensivos. De hecho lo decisivo en am-

24. Popper, K. R.; Los dos problemas fundamentales de la epistemología. Basado en los manuscritos de los años 1930-1933, Tecnos, Madrid, 2007.

25. Artigas, M.; Lógica y ética en Karl Popper: (se incluyen unos comentarios inéditos de Popper sobre Bartley y el racionalismo crítico), Eunsa, Pamplona, 1998.

Thémata. Revista de Filosofía №55 (2017) pp.: 83-130. 


\section{El legado del positivismo lógico, 50 años después. \\ La autoinmunidad hipercrítica del neodualismo postanalítico}

bos casos consistiría en la valoración que merecen los resultados obtenidos de un modo pragmático por los distintos procedimientos de explicación o de comprensión, según fueran verificables o simplemente refutables, a fin de poder garantizar así el buen uso que en cada caso se hiciera del lenguaje ${ }^{26}$.

Se otorgó así en un segundo momento una primacía a un debate semiótico donde se pretendía garantizar el buen uso del lenguaje. De hecho sin disponer de un lenguaje ideal perfecto tampoco sería posible garantizar una correcta falsación o refutación de los procesos de comprensión intersubjetiva humana. A este respecto se trató de enjuiciar las diversas posturas heurísticas en razón primeramente de las consecuencias beneficiosas o perjudiciales que habrían acabado teniendo determinadas explicaciones heurísticas para el avance de la ciencia. Pero, posteriormente, también se tendría en cuenta el buen o mal uso que en cada caso se hacía del lenguaje científico en los procesos de comprensión recíproca de una consecuencia o de una determinada hipótesis De ahí que a lo largo del debate se alcanzaran diversas propuestas convergentes, a favor y en contra, de una metodología u otra. Todo dependía según se otorgara una mayor importancia a los problemas metodológicos o a los estrictamente semióticos, a los procesos de explicación o de comprensión científica. Es decir, a la justificación de un lenguaje ideal perfecto válido para los procesos de explicación experimental o bien a la elaboración de diversos lenguajes pragmáticos simplemente especializados que serían especialmente válidos para determinados procesos de comprensión ${ }^{27}$.

De hecho el modo de obrar explicativo-comprensivo de la ciencia con frecuencia siguió adoleciendo de un fuerte dogmatismo inductivista, o de una pretenciosa autoinmunidad falibilista en si misma pluralista, a pesar de las reiteradas advertencias en sentido contrario. Especialmente cuando la ciencia se interpretó como un saber fuertemente sistemático en el que prevalece un principio de coherencia, sin querer reconocer las limitaciones de los procedimientos inductivos, o simplemente decisionitas, de los que con frecuencia se sirve. Hasta el punto que en estos casos tampoco se pudo admitir la presencia de anomalías que pueden hacer peligrar la pretendida solidez del ideal positivista de una ciencia unificada. Al menos así habría sido postulado inicialmente por Russell y Wittgenstein, a pesar de los pocos argumentos a favor que en su caso pudieron aportar. Pero de igual modo ahora se pretendería seguir admitiendo dicho ideal de un modo tácito, en la medida que las diversas ciencias se demuestran

26. Rescher, N.; Cognitive Pragmatism. The Theory of Knowledge in Pragmatic Perspective, University of Pittsburgh, 2001.

27. Shook, J. R.; Margolis, J. (eds); A Companion to Pragmatism, Blackwell, Oxford, 2006.

Thémata. Revista de Filosofía N55 (2017) pp.: 83-130. 
suficientemente seguras a la hora de justificar sus respectivos procesos de explicación experimental o de comprensión de presupuestos, sin necesidad de recurrir a fuentes de conocimiento ajennas Sin embargo, por otra parte, los proyectos programáticos positivistas lógicos y racionalistas-críticos estarían continuamente queriendo hacer ver su creciente poder de verificación y de refutación ${ }^{28}$.

En uno casos se pretendía hacer tambalear el dogmatismo inductivo en el que con frecuencia se fundamentan los experimentos cruciales más audaces de las ciencias aparentemente más rigurosas. En otro caso se quería más bien confirmar la autoinmunidad falibilista de sus respectivos presupuestos metateóricos, a pesar de tener que ir en contra de sus propios proyectos progrméticos. En este sentido se fomentó una actitud generalizada de resignación observando con una cierta imperturbabilidad estoica estos aparentes contratiempos, para sacar una consecuencia muy precisa, a saber: en cualquier caso el "nuevo dualismo "explicativo-comprensivo debería seguir la anterior estrategia del positivismo lógico, a saber: por un lado, aceptar un dogmatismo inductivo inicial propio de la explicación científica; y, por otro lado, fomentar una ulterior "autoinmunidad" falibilista que ahora viene exigida por la comprensión recíproca de determinados presupuestos de la ciencia. Sólo así se podría acabar comprobado cómo el simple paso del tiempo podría acabar dando por bueno el éxito alcanzado o el fracaso cosechado por una determinada teoría. Con la ventaja añadida de que de este modo también se podría confirmar la posibilidad de encontrar un posible lenguaje ideal aún más perfecto, ya se justifique en nombre de la práctica vulgar de la ciencia, o en nombre de un principio pragmático transcendental, como ahora postularán respectivamente von Wright y Apel ${ }^{29}$.

\section{1.d. El dilema explicación-comprensión en los procesos gnoseoló- gicos científicos.}

De todos modos von Wright y Apel señalan cómo el "nuevo dualismo" post-analítico habría acabado reincidiendo en una segunda clara divergencia que anteriormente también se habría hecho presente entre las propuestas del primer Wittgenstein y de Popper. Se trataría del modo respectivo tan distinto de concebir los presupuestos metateóricos o simplemente crítico-transcendentales de los correspondientes procesos de explicación experimental y de comprensión teleológica de la investigación cien-

28. Richter, D., Wittgenstein at His World, Continuum, London, 2005.

29. Elster, J.; Reason and Rationality, Princeton University, Princeton, 2008.

Thémata. Revista de Filosofía №55 (2017) pp.: 83-130. 


\section{El legado del positivismo lógico, 50 años después. \\ La autoinmunidad hipercrítica del neodualismo postanalítico}

tífica. En el caso del primer Wittgenstein se habría fomentado un doble dogmatismo inductivo en la interpretación tanto del uso del lenguaje como de la explicación de la experiencia, sin establecer una clara separación en el modo de proceder en ambos casos. En cambio, en el caso de Popper, la lógica de la ciencia se habría apropiado de una "autoinmunidad" falibilista, que le hace confiar en el logro de posible mejor comprensión de las teorías y del lenguaje semiótico de cada una de las ciencias, salvo que se pretendan fomentar un falibilismo dada vez más radicalizado como el antes señalado ${ }^{30}$.

Se trata en cualquier caso de un dilema que surge a la hora de tratar de justificar el paralelismo lógico físico postulado por el positivismo lógico entre la mente y el mundo. Sin embargo dicho paralelismo ahora también se seguiría haciendo presente a largo plazo en las posturas defensoras de este "nuevo dualismo" positivista lógico, dando lugar a dos posibles posturas: $\mathrm{O}$ bien se concibe este paralelismo como una condición de posibilidad y de sentido de la efectiva referencia compartida a unas mimas explicaciones experimentales por parte de los distintos interlocutores afectados, a pesar de tratarse de una presunción profundamente dogmática. $\mathrm{O}$ bien se concibe este paralelismo como consecuencia de un decisionismo crítico que admite la posibilidad de formas múltiples de comprensión divergente, a pesar de presuponer en cada caso formas de autoinmunidad que son recíprocamente incompatibles. Hasta el punto que se tuvo que admitir la posibilidad de formalizar un mismo hecho de la experiencia de formas que son gnoseológicamente divergentes, aunque ello pudiera suponer una conclusión profundamente escéptica respecto del posible avance de la ciencia ${ }^{31}$.

En efecto, en el Tractatus se parte de la presunción dogmática de la existencia de un paralelismo lógico-físico entre la mente y el mundo. En cambio, en "La lógica de la investigación científica" se parte de la presunción contraria: la posibilidad de múltiples formas refutables de articular las relaciones entre la mente y el mundo, sin que se pueda saber de antemano cuales son las acertadas o las equivocadas. Sin embargo ahora en ambos casos se partiría de la aceptación de un mismo postulado, a saber: la necesidad de asignar una explicación inductiva o una autoinmunidad comprensiva falibibilista a determinados principios, ya se formules con la pretensión de comprobar la efectiva verificación de sus posibles consecuencias, o con la pretensión de justificar las efectiva comprensión de sus respectivos presupuestos. En efecto, solo mediante esta duplicación

30. Popper, K. R. (2007), Los dos problemas fundamentales de la epistemología. Basado en los manuscritos de los años 1930-1933, Tecnos, Madrid.

31. Schulte, J.; Ludwig Wittgenstein, Suhrkamp, Frankfurt, 2005.

Thémata. Revista de Filosofía $\mathrm{N}^{\circ} 55$ (2017) pp.: 83-130. 
de funciones se podría seguir aspirando al logro de una articulación más efectiva entre las correspondientes ciencias unificadas, según aquellos criterios heurísticos que previamente habrían sido estipulados de un modo dogmático por el positivismo lógico, pero que ahora lograrían justificarse de un modo crítico ${ }^{32}$.

Sin embargo ahora este mismo ideal de las ciencias unificadas se podrían justificar de un doble modo: o bien mediante un proceso de explicación positivista lógico de sus propias consecuencias, o bien mediante un proceso de comprensión racionalista-crítico de la autoinmunidad de los respectivos presupuestos que están sobreentendido tras el uso en sí mismo decisionista o convencional del lenguaje. De todos modos a este modelo explicativo-comprensivo también se objeta, que en el caso de admitir esta posibilidad, se estaría introduciendo un tercer presupuesto metateórico igualmente dogmático, a saber: Se estaría perpetuando la existencia de un isomorfismo entre los ahora llamados hechos atómicos y las correspondientes proposiciones atómicas, así como con las diversas formas de lenguaje científico, volviendo a las antiguas paradojas que ya se hicieron presentes anteriormente en el positivismo lógico. A este respecto ya Quine en los años 30 habría sido el primero en denunciar lo que en su caso denominó los dos dogmas del empirismo lógico. Es decir, el hecho de presuponer dos supuestos de imposible justificación, como ahora sucede con el paralelismo lógico-físico entre la mente y el mundo, y de una armonía lingüistica preestablecida entre los diversos interlocutores afectados. Con el agravante de que el "nuevo dualismo" pretendería incorporar estos dos presupuestos a su propio proyecto programático, sin considerarlos dos nuevas formas de dogmatismo. En su lugar se conciben estos presupuestos a modo de dos postulados que se afirman de un modo explicito al modo de una condición de posibilidad y de sentido de cualquier proceso de investigación heurística referido a la experiencia ${ }^{33}$.

A este respecto, según von Wright y Apel, tanto el "Tractatus", como "La lógica de la investigación científica", acabarían introduciendo una paradoja pragmático-transcendental muy similar. En ambos casos se remiten a unos postulados teóricos que en principio contradicen su propio proyecto programático, aunque cada uno le acabara otorgando un sentido vicioso o virtuoso muy diferente. Especialmente a la hora de pretender justificar la posibilidad de un nivel metateórico de sus respectivas lógicas de la ciencia, que contrarrestase la aparición de estas posibles paradojas. En efecto, tanto en un caso como en el otro, se debe partir de la presunción

32. Tallis, R.; On the Edge of Certainty. Philosophical Explorations, MacMillan, Hampshire, 2000.

33. Russell, B.; Our Knowledge of External World: as a field for Scientific Method in Philosophy, Blackwell, Oxford, 1998.

Thémata. Revista de Filosofía N55 (2017) pp.: 83-130. 


\section{El legado del positivismo lógico, 50 años después. \\ La autoinmunidad hipercrítica del neodualismo postanalítico}

a favor de admitir determinados criterios de demarcación entre la ciencia y la no ciencia, ya sea en virtud de un dogmatismo explicativo inductivo o de una determinada autoinmunidad comprensiva falibilista, a pesar de carecer de una justificación adecuada de naturaleza metodológica o semiótica. En efecto, sólo si se dispone de una justificación adecuada, será posible determinar el límite preciso hasta donde puede llegar una aplicación razonable de un principio de explicación inductiva o de refutación comprensiva. De hecho ya no se pueden considerar científicos una forma de saber explicativa o comprensiva que intente prescindir de estos criterios ${ }^{34}$.

En este sentido los procedimientos inductivos del positivismo lógico se acabaron apropiando de unos criterios de explicación que deberían ser capaces de demarcar lo que era ciencia respecto de la no-ciencia o pseudociencia. Por su parte la "lógica" popperiana de la refutación se acabaría apropiando de un modo autoinmune cualquier proceso de universalización pseudo-científica. Precisamente en la medida que un saber rechaza la aplicación de un principio de verificación inductiva o de refutación hipotética deductiva, tampoco podría justificar su carácter de ciencia, pasando a ser considerada una no-ciencia. En ambos casos se formulan estos criterios de demarcación con la pretensión explícita de excluir a la metafísica clásica, ya sea por carecer de una base inductiva suficientemente contrastada o por no poder justificar su pretendida autoinmunidad frente a la experiencia. Sin embargo las corrientes actuales del "nuevo dualismo" post-analítico querrán ver en este tipo de criterios una nueva forma de acceder a una "nueva metafísica" que, más que como una justificación racional de la experiencia, se concibe como una metateoría de la ciencia ${ }^{35}$.

En este sentido el Tractatus habría acabado otorgando en todo momento una validez dogmática al pretendido paralelismo lógico/físico existente entre lo teórico y lo observacional, entre la explicación y la comprensión, entre el inicial proyecto programático positivista lógico y sus posteriores aplicaciones prácticas cada ver más universales. Sin embargo su propuesta escondía una segunda motivación que inicialmente podría pasar más desapercibida. Se trataba de la única forma posible de fijar los

34. Martínez Solano, J. F.; El problema de la verdad en K.R. Popper. Reconstrucción histórico-sistemática, Netbiblo, Oviedo, 2005.

35. A este respecto Apel afirma: >"El neowittgenstianismo se vio obligado a tener que justificar una cada vez más completa disyunción entre los posibles juegos del lenguaje (... salvo que) pudiera estar vigente de un modo "a priori" esta nueva lógica de lo pragmático-transcendental (...). Así fue como el "nuevo dualismo" postwittgenstteniano interpretó la situación de complementariedad pragmático-transcendental respecto de la verdad"<. Apel, K. O.; EVKTPS, p. 274. McManus, D.; The Enchantement of Words. Wittgenstein's Tractatus Logico-Philosophicus, Clarendon, Oxford University., Oxford, 2006.

Thémata. Revista de Filosofía Nº55 (2017) pp.: 83-130. 
requisitos exigidos a los procesos de inducción de la ciencia, así como las condiciones que debería cumplir una armonía lingüistica preestablecida entre los diversos interlocutores afectados. Sólo así se podrían excluir todas aquellas formas de explicación que no pueden ser ciencia ${ }^{36}$.

Por su parte, La lógica de la investigación científica de Popper habría acabado otorgando una validez autoinmune a los primeros principios de la razón natural, así como a la aceptación de un principio de proliferación semiótica a la hora de justificar una posible intercomunicación lingüística. Sólo así se podrían de alcanzar una posible comprensión de los distintos supuestos compartidos que deben ser admitidos en una justificación científica, rechazando todos los que no cumplan estas condiciones. De este modo las nuevas corrientes del "nuevo dualismo" invirtieron el sentido tan despectivo que Carnap había otorgado a los llamados dos dogmas del empirismo, para otorgarle un sentido virtuoso muy distinto. No se trataba de otorgar un valor desmedido a las conclusiones científicas, sino más bien lo contrario: tratar de establecer unos límites que no se podrían sobrepasar por dichos principios, ya sea por no poder alcanzar la base inductiva mínima necesaria exigida en cada caso, ya sea por otorgarles una autoinmunidad convencional desproporcionada y carente de la más mínima justificación ${ }^{37}$.

Pero, a pesar de la convergencia interna postulada entre dos proyectos científicos tan diferentes, sin embargo von Wright y Apel consideran que en ambos casos acabarían prevaleciendo una presunción diferente, a saber: en el caso de Russell y el primer Wittgenstein la presunción a favor del mantenimiento de determinado paralelismo lógico/físico en sí mismo dogmático, que ahora se afirman como una condición de posibilidad y de sentido mínima respecto de la posterior explicación de un posterior hecho de la experiencias; y, en el caso de Popper, la presunción contraria a favor de la "autoinmunidad" falibilista a largo plazo de una armonía lingüistica preestablecida que ahora se establece como una condición de posibilidad y de sentido mínima para la efectiva comprensión de una determinada proposición científica. En este sentido el "nuevo dualismo" acabaría comprobando como las propuestas de Russell y el primer Wittgenstein, así como el falsacionismo de Popper, acabarían convergiendo en una última propuesta absolutamente necesaria, aunque ahora habría que justificarla de un modo crítico-transcendental totalmente diferente, a saber: la aceptación de un presupuesto crítico de positivismo lógico, como ahora sucede con el inicial paralelismo lógico/físico que se establece entre la mente y el

36. McGuinness, B.; Young Ludwig. Wittgenstein's Life 1889-1921, Oxford University, Oxford, 2005.

37. Böhler, D. ; Kettner, M.; Skirbekk, G. (2003), Reflexion und Verantwortung: auseinandersetzungen mit Karl-Otto Apel, Suhrkamp, Frankfurt. , 2005.

Thémata. Revista de Filosofía №55 (2017) pp.: 83-130. 


\section{El legado del positivismo lógico, 50 años después. \\ La autoinmunidad hipercrítica del neodualismo postanalítico}

mundo, y con la existencia de una armonía semiótica preestablecida entre los distintos interlocutores afectados. De hecho se trata de dos presupuestos que señalan los límites que debe tener la aceptación de una mayor base inductiva o la naturaza cada vez más "autoinmune" frente a todo posible oponente de los presupuestos últimos de la ciencia. De hecho se trata de dos supuestos absolutamente necesarios para una actitud verdaderamente crítica frente al inevitable progreso de la ciencia experimental. Sin embargo, no se pueden afirmar como metas ya conseguidas, sino más bien como postulados que aún están por conseguir ${ }^{38}$.

En cualquier caso los seguidores de un “nuevo dualismo" post-analítico, al menos según Von Wright y Apel, consideraron que se podrían desactivar las posibles discrepancias entre las propuestas positivistas-lógicas de Russell y el primer Wittgenstein y las racionalistas-críticas de Popper. Es más, se admitió que se podrían acabar conciliando siempre que se admitiera una tercera alternativa todavía no examinada, a saber: elaborar un nuevo modelo de cobertura legal entre hechos y leyes, que fuera capaz a su vez de contrarrestar el recurso a planteamientos abusivamente inductivos o extralimitadamente falsacionistas. A este respecto sus propuestas fueron aparentemente antitéticas, aunque en el fondo eran complementarias. En cualquier caso la estrategia seguida por el "nuevo dualismo" post-analítico tampoco pretendió desnaturalizar o simplemente desvirtuar las tesis principales del positivismo lógico, sino que simplemente pretendió resaltar lo que en cada caso tiene de más valioso ${ }^{39}$. Veámoslo.

\section{1.e. El dilema entre la unidad explicativa y el pluralismo comprensivo.}

En este sentido, según von Wright y Apel, el "nuevo dualismo" post-analítico habría localizado la presencia a lo largo del debate ahora iniciado entre Russell, el primer Wittgenstein y Popper de una segunda clara divergencia. Se trata del modo respectivo tan antitético de abordar los presupuestos semióticos o simplemente lingüísticos de la explicación y de la comprensión heurística. Surgió así un dilema que progresivamente se acabó enconando cada vez más entre la exigencia positivista-lógica de remitirse a un lenguaje ideal unificado valido para todas las ciencias, o el reconocimiento de una pluralidad de lenguajes semióticos específicos de cada ciencia. En el primer caso se justificarían en virtud de una axiomática

38. Cf. Peter, F.; Schmid, H. B.; Rationality and Commiment, Oxford University, Oxford, 2007.

39. Boghosian, P.; El miedo al conocimiento. Contra el relativismo y el constructivismo, Alianza, Madrid, 2009.

Thémata. Revista de Filosofía Nº5 (2017) pp.: 83-130. 
dogmática, mientras que en el segundo se abrogarían una auto-inmunidad pluralista falibilista en virtud de su carácter mancomunado comprensivo meramente convencional. Máxime si ambas exigencias generan confrontaciones y discrepancias recíprocas entre ellas, aunque no siempre tuvieran que acabar siendo absolutamente incompatibles ${ }^{40}$.

En efecto, así como en el Tractatus se parte de la presunción aparentemente dogmática de la existencia de un lenguaje ideal perfecto propio de las ciencias unificadas, en el fondo para el "nuevo dualismo" se trata de una simple pretensión que aún esta muy lejos de haberse alcanzado. En realidad se trata de un presupuesto verdaderamente "autoinmune" que ahora se afirma como una condición de posibilidad y de sentido que vendría exigida a largo plazo por el mantenimiento de una efectiva conmensuración recíproca entre los distintos interlocutores afectados. Además, se exigiría en estos casos un seguimiento de los criterios estipulados a tal efecto por el positivismo lógico: es decir otorgándole una efectiva verificación explicativa y una subsiguiente "autoinmunidad" comprensiva falibilista frente a todo posible oponente. De hecho se trata de simples convenciones que perfectamente podrían permitir la estipulación de un consenso o acuerdo mutuo a este respecto ${ }^{41}$.

De todos modos algo similar ocurre con la presunción aparentemente "autoinmune" que La lógica de la investigación científica otorga a determinados principios mediante los que se regula la falsación o refutación de una hipótesis. También en este caso tampoco el principio de falsación se puede refutar a sí mismo ya que en realidad se trata de un principio muy distinto: en realidad se trata de una exigencia teórica que ahora se afirma como un presupuesto y condición de sentido que viene exigido a toda hipótesis científica por su obligada confrontación con la experiencia. A este respecto el "nuevo dualismo" hace notar como el resultado buscado no tiene que ser necesariamente la refutación de una hipótesis. También puede tratarse perfectamente de un simple estado de mayor vaguedad, probabilidad o indeterminación. Lo único decisivo es que la proposición propuesta pierda de universalidad inicialmente asignada, aunque la forma de ser refutada puede ser en cada caso muy distinta ${ }^{42}$

A este respecto en La lógica de la investigación científica" también termina apareciendo una paradoja heurística similar a la que aparecía

40. Hacker, P. M. S.; Wittgenstein: Connections and Controversies, Clarendon, Oxford University, 2001.

41. Kölbel, M.; Weiss, B. (eds) (2004), Wittgenstein's Lasting Significance, Routledge, London.

42. A este respecto afirma Popper: >"La tentativa wittgensteniana de desenmascarar el problema de la inducción como un pseudoproblema vacío, ha sido expresada por Schlick con las siguientes palabras: "El problema de la inducción consiste en preguntar por la justificación lógica de los enunciados universales acerca de la realidad.... Reconocemos con Hume, que no existe semejante justificación lógica: no puede haber ninguna, por el simple hecho de que no son

Thémata. Revista de Filosofía $\mathrm{N}^{\circ} 55$ (2017) pp.: 83-130. 


\section{El legado del positivismo lógico, 50 años después. La autoinmunidad hipercrítica del neodualismo postanalítico}

anteriormente en el Tractatus, aunque sea en un sentido inverso. En efecto, también en "La lógica" popperiana se parte de la presunción a favor de un pluralismo semiótico falibilista, dejando indeterminado cual es el mejor o el peor. Se dejan así diversas alternativas abiertas a los procesos de creciente universalización con tal de que se reconozca la necesidad de someterse a una posible refutación ulterior. Sin embargo, incluso en el caso de ser refutadas, siempre estos diversos proyectos programáticos acaban saliendo aún más reforzados de este tipo de situaciones de aparente fracaso, como las ahora descritas. En efecto, en estos casos la posible refutación de una hipótesis debería compensarse posteriormente con un nuevo proceso heurístico de universalización aún mayor, que a su vez también se debería someter a un proceso similar de refutación aún más estricta, pero que siempre deberá venir acompañado de un proceso de creciente universalización. Hasta el punto que la "lógica" popperiana de la refutación acaba fomentando un creciente pluralismo semiótico falibilista. Es decir, tendrá que recurrir a la única estrategia "autoinmune" comprensiva falibilista que siempre tiene asegurada una correcta respuesta frente a cualquier posible oponente con tal de estar abierta a este anterior doble proceso heurístico de refutación ulterior y de subsiguiente ampliación de horizontes. En este sentido, "La lógica" popperiana, presupone una clara orientación final en un proceso de hallazgo de la verdad. Se postula así lograr en un momento final, lo que para el Tractatus estaba formulado desde un principio. Es decir, también en su caso se persigue el establecimiento de un paralelismo lógico/físico entre la mente y el mundo, así como de una armonía semiótica preestablecida. Lo única diferencia es que en vez de establecerla desde un principio, como en el Tractatus, ahora "La lógica" popperiana la postula como un resultado por alcanzar el final del proceso ${ }^{43}$.

En este sentido para el "nuevo dualismo" post-analítico el Tractatus permite seguir otorgando una validez dogmática a toda explicación científica el presupuesto semiótico de un lenguaje ideal perfecto o unificado, a pesar de tampoco poder aportar ninguna prueba definitiva al respecto. Por su parte, "La lógica de la investigación" popperiana también permite seguir postulado la concesión de una "autoinmunidad comprensiva falibilista" a toda pretensión de universalidad que haya superado la prueba de someterse a una posible refutación. Sólo se exige que previamente exista el efectivo compromiso de seguir aplicando de un modo ininterrumpido este tipo de exigencias heurísticas. Sólo se acabará este proceso cuando se vea

auténticos enunciados"<. Popper, K.; LF, p. 11; LSD, p. 36-37; LIC, p. 36. Cf. Pears, D.; Paradox and Platitude in Wittgenstein's Philosophy, Clarendon, Oxford University, Oxford, 2006.

43. Cerezo, M.; The Posibility of Language. Internal Tensions in Wittgenstein's 'Tractatus', CSLI, Stanford (CA); 2005.

Thémata. Revista de Filosofía N55 (2017) pp.: 83-130. 
efectivamente confirmado de un modo irrefutable el paralelismo lógico/ físico y la armonía lingüistica preestablecida al final del proceso. En cualquier caso, tanto el primer Wittgenstein como Popper, mantuvieron una presunción irrenunciable a favor de seguir recurriendo a determinados "dogmatismos" explicativos inductivos cada vez más unificados o a seguir atribuyendo una "autoinmunidad" comprensiva falibilista cada vez mas diferenciada" respecto a determinados principios. Sin embargo la propia práctica científica diaria acabaría demostrando que perfectamente podrían formularse de un modo muy diferente, ya sea por consenso, o por simple reconocimiento de la respectiva vaguedad o simple probabilidad. Hasta aquí llegó el acuerdo entre von Wright y Apel en el modo de interpretar el "nuevo dualismo" post-analítico, pero también surgieran divergencias muy notables entre ambos a la hora de concebirlo en la práctica. Veámoslas ${ }^{44}$.

\section{Wright, 1971: La "autoinmunidad" hipercrítica del "nuevo dualismo"}

Von Wright en 1971, no sólo reconstruyó el proceso histórico de convergencia ahora descrito, También analizó las nuevas virtualidades abiertas por el legado dejado por el positivismo lógico. A este respecto von Wright en Explicación y comprensión (1971) habría tratado de justificar la aparición de un "nuevo" modelo de cobertura legal que fuera capaz de integrar las propuestas explicativas del positivismo lógico del primer Wittgenstein y las pretensiones comprensivas del racionalismo crítico de Popper, con un propósito muy definido, a saber: mostrar como el "nuevo dualismo" postanalítico también podría acabar concibiendo las estrategias heurísticas tan opuestas del Tractatus y de La lógica de la investigación científica como si fueran intercambiables entre sí; es decir, como si se tratara de dos fases instrumentales complementarias de un mismo modelo nomológico deductivo superior que las abarca a ambas por igual. De hecho todas estas propuestas de integración recíproca se acabarán materializando en el llamado modelo explicativo-comprensivo de Popper-Hempel-Oppenheim; es decir, un modelo que trataría de aprovechar las indudables ventajas explicativas de las respectivas propuestas de Russell y del primer Wittgenstein, con las virtualidades comprensivas de las propuestas de Popper, tratando de evitar a su vez sus posibles deficiencias. De hecho en virtud de este único modelo de cobertura legal se acabarán introduciendo nuevas leyes regidas por una necesidad explicativa cada vez más estricta, junto

44. Searle, John R.; Philosophy in a New Century. Selected Essays, Cambridge University, Cambridge, 2008.

Thémata. Revista de Filosofía №55 (2017) pp.: 83-130. 
con un horizonte de comprensión cada vez más abierto. Precisamente por eso también se tuvo que abrir alternativamente a una posible refutación aun más amplia en virtud de sus consecuencias en contrario, sin tampoco poder cuestionar por ello la necesidad de una apertura unos presupuestos "autoinmunes" falibilistas mínimos que serían específicos de cualquier proceso hermenéutico de comprensión recíproca. Según von Wright, sólo así será posible alcanzar un progresivo acercamiento a la verdad, a pesar de nunca poderlo lograr completamente ${ }^{45}$.

\section{2.a. Hacia una integración inductivo-falsacionista de saber científico}

Evidentemente la posibilidad de integrar los planteamientos inductivistas explicativos del positivismo lógico de Russell y del primer Wittgentein, así como las propuestas comprensivas falsacionistas de Popper, requería introducir algunos pequeños cambios en los respectivos proyectos programáticos. Sin embargo siempre se debería respetar su núcleo esencial más irrenunciable, sin tampoco poderlo desnaturalizar ni desvirtuar arbitrariamente. En es sentido el "nuevo dualismo" postanalítico, según von Wright, propuso el denominado modelo Popper-Hempel-Oppenheim que hacía posible la integración del los modelos inductivistas y falsacionistas, explicativos y comprensivos, con solo introducir dos pequeños cambios ${ }^{46}$ :

1) Completar la lógica inductiva explicativa del primer Wittgenstein con otras formas de experimentación mediante las que también se puede fomentar un isomorfismo o un paralelismo lógico/físico que no sea tan rígido; es decir, permitiendo la entrada de otras formas de saberes experimentales más diversificados, subalternados y abiertos. Sólo así las propuestas heurísticas del positivismo lógico no sólo se podrán aplicar a las ciencias naturales, especialmente la física, sino que también se podrían extrapolar al resto de las ciencias, incluidas las humanas y sociales. De este modo sería posible introducir una gradación entre dos posibles extremos de ciencia explicativa-inductivista o positiva, a saber: por un lado, la ciencia explicativa mínima o estricta, que cumple todos los requisitos normativos ahora exigidos por el modelo experimental positivista lógico para toda forma de saber, como por antonomasia ocurre con la física. Y, por otro lado, la ciencia explicativa ampliada o simplemente mas compleja o incluso heterodoxa, que admite una apertura máxima a otro tipo de añadidos experimentales complementarios igualmente necesarios, siempre que

45. Popper, K.; Bosetti, G. (interview); Lesson of this Century. With Two Talks on Freedom and the Democratic State, Routledge, London, 2000.

46. Mounce, H. O.; The two Pragmatisms. From Peirce to Rorty, Routledge, London, 1997.

Thémata. Revista de Filosofía $\mathrm{N}^{\circ} 55$ (2017) pp.: 83-130. 
simultáneamente tampoco se renuncie al mínimo heurístico exigido por el positivismo lógico a toda forma de saber ${ }^{47}$.

2) Anteponer a la lógica comprensiva falsacionista de la refutación de hipótesis de Popper aquellos otros procedimientos inductivos que desde su inicio se presuponen. De este modo los procesos comprensivos de falsación se podrán encaminar al reforzamiento de un previo criterio de demarcación entre lo teórico y lo observacional, entre lo racional y lo fáctico, entre la explicación y la comprensión. Sólo así se podrá dar entrada a otras formas de saberes hermenéuticos o interpretativos cada vez más consolidados, globales y autoinmunes. Hasta el punto que las propuestas heurísticas racionalistas-críticas no sólo se podrán aplicar a las ciencias naturales, incluida la física o la biología, sino que también se podrán extrapolar al resto de las ciencias históricas y sociales ${ }^{48}$.

De este modo también sería posible introducir una gradación entre dos extremos de las llamadas ciencias hermenéuticas o interpretativas, a saber: por un lado, la ciencia hermenéutica mínima, que cumple los requisitos normativos más estrictos ahora exigidos por el modelo comprensivo o racionalista-crítico a toda forma de saber, como por antonomasia ocurre con la propia historia de la ciencia. Y, por otro lado, la ciencia hermenéutica ampliada o simplemente más compleja o incluso heterodoxa, que admite una apertura máxima a otro tipo de añadidos comprensivos complementarios igualmente necesarios, aunque sin renunciar en ningún momento al mínimo heurístico exigido por el racionalismo crítico a toda forma de saber ${ }^{49}$.

En este sentido Wright también detectó la presencia en el denominado modelo Popper-Hempel-Oppenheim de un doble inductivismo y falsacionismo similar al que anteriormente se habría hecho presente en el Tractatus y en La lógica de la investigación popperiana. Con la única diferencia de que ahora se habría intentado integrarlos mutuamente ente sí. En efecto, anteriormente ya Wittgenstein había defendido un induc-

47. Stroud, B.; Meaning, Understanding, and Practice. Philosophical Essays, Oxford University, Oxford, 2000.

48. Bartley, W. W.; The Retreat to Committment, New York, 1962.

49. A este respecto Wright afirma: >"Llevado a sus respectivos extremos, el positivismo (del primer Wittgenstein) y el convencionalismo (o racionalismo crítico popperiano) vienen a oponerse en un sentido parecido a como se oponen entre sí un empirismo extremado y un extremado racionalismo. Pero es relativamente fácil hallar una fórmula de compromiso. Un positivista razonable estará de acuerdo en que algunos principios científicos tienen el carácter de verdades analíticas mientras que otros son palmariamente generalizaciones empíricas. Reconocerá además que la línea divisoria entre ambas categorías no ha dejado de ser a menudo fluctuante en el curso del desarrollo histórico de la ciencia"<. Wright, G. H. von; EU, p. 20; EC, p. 41. Cf. Freudiger, J.; Graeser, A.; Petrus, K. (Hrsg.); Der Begriff der Erfahrung in der phiolosophie des 20 Jahrhunder, C. H. Beck, München, 1996.

Thémata. Revista de Filosofía $\mathrm{N}^{\circ} 55$ (2017) pp.: 83-130. 
tivismo explicativo mínimo y Poper una aplicación de un falsacionismo comprensivo con la máxima amplitud posible respecto de los ámbitos más distintos de la racionalidad científica. Sin embargo ahora el modelo Popper-Hempel-Oppenheim pretendía integrar ambos proyectos de investigación, aunque con una circunstancia añadida. En efecto, ahora se comprueba como el "nuevo dualismo" post-analítico habría intentado eludir este tipo de planteamientos tan unilaterales. De ahí que se reconozca la posible existencia de diversos grados tanto en las explicaciones inductivas como en los procesos de comprensión falsacionista por parte de cada saber científico en particular, aunque sin terminar de articularlos recíprocamente entre sí. Especialmente cuando se comprueba que ambos procesos se necesitan, en la medida que a su vez también se contraponen ${ }^{50}$.

\section{2.b. El tránsito bipolar desde el positivismo lógico hasta el "nuevo dualismo"}

En cualquier caso la aceptación de una bipolaridad inductivo-falsacionista en la configuración de las ciencias positivas exigió que el modelo Popper-Hempel-Oppenheim diera un paso más, a saber: la aceptación de una articulación teórico/observacional y comprensiva/explicativa aún más sofisticada, que permitiera establecer un equilibrio entre ambas facetas de su respectivo método. Es decir, un modelo comprensivo/explicativo que no exigiera una refutación de todo lo comprendido por una ciencia por el mero hecho de encontrar un simple hecho que lo contradiga, como pretendió Popper. Ni que tampoco exigiera admitir una imposible verificación exhaustiva de todas las posibles explicaciones inductivas, como en principio pretendía alcanzar el modelo Russell-Wittgenstein ${ }^{51}$.

En su lugar el "nuevo dualismo" de von Wright hace notar como el llamado modelo Popper-Hempel-Oppenheim habría postulado más bien la posibilidad de aprovechar aquellas posibles refutaciones generadas por el método de falsación de hipótesis respecto a las generalizaciones inductivas abusivas, con un objetivo muy claro: aspirar en su lugar a una comprensión aún mas universal por parte del modelo de cobertura legal, siempre que pudiera ser objeto de una refutación mediante una explicación aun más puntual, incluso de un único caso De todos modos los sucesivos pasos de este proceso de explicaciones cada vez más universalizantes también deberían estar abiertos a una aplicación explicativa lo más puntual posi-

50. Albert, H.; Traktät über kritische Vernunft, Tübingen, 1968.

51. Misak, C.; Truth, Politics, Morality. Pragmatism and Deliberation, Routledge, London, 2000.

Thémata. Revista de Filosofía Nº55 (2017) pp.: 83-130. 
ble de un principio de refutación . Evidentemente un paso tan ambicioso, se tuvo que someter a un posterior proceso de confirmación mediante una estrategia inductiva todavía más arriesgada en sus pretensiones de creciente explicación universal. De hecho cualquier recuso a la experiencia podría acabar en una simple refutación de la hipótesis propuesta; es decir, debería seguir estando abierta a que un simple hecho de la experiencia pudiera contradecir todo lo logrado hasta entonces, para, a partir de ahí, tener que comenzar de nuevo a tratar de elaborar nuevas hipótesis igualmente refutables ${ }^{52}$.

En este sentido el "nuevo dualismo" de von Wright advirtió la referencia en el Tractatus de Wittgenstein a un marco de cobertura legal de carácter explicativo, que a su vez habría estado implícito en los distintos procesos de creciente generalización inductiva, aunque nunca se hubiera descrito explícitamente. En este sentido von Wright opina que en el Tractatus se reflejan de un modo paradigmático los tres presupuestos básicos que a su vez hacen posible el peculiar modelo de cobertura legal que acabó caracterizando al positivismo lógico de comienzos de siglo ${ }^{53}$ :

a) El monismo metodológico que postula una sola forma posible inductiva valida de explicar científicamente la experiencia ${ }^{54}$;

b) La comprensión de un ideal matemático de perfección con la consiguiente justificación axiomática de un lenguaje científico "autoinmune" frente a toda posible crítica. Además, se trata de un ideal que debería ser plenamente compartido por toda la comunidad de los investigadores, en virtud de su validez intrínseca, sin necesidad de recurrir a un principio de refutación. Hasta el punto que esta nueva forma de lenguaje matemático ideal o axiomático ahora se afirma como una condición de posibilidad y de sentido de las propias explicaciones experimentales, dado que de no admitirse tampoco sería posible una comunicación científica verdaderamente compartida ${ }^{55}$;

c) La justificación de un tipo de explicación científica capaz de subsumir teóricamente todo el conjunto de aquellas experiencias previas en un lenguaje ideal verdaderamente unificado que sería válido para todos los

52. Cf. Charles, D.; Aristotle on Meaning and Essence, Clarendon, Oxford University, 2000.

53. Taylor, C.; Argumentos filosóficos. Ensayos sobre el conocimiento, el lenguaje y la modernidad, Paidós, Barcelona, 1997.

54. Lupia, A.; McCubbins, M. D.; Popkin, S. L. (ed.); Elements of Reason. Cognition, Choice, and the Bounds of Rationality, Cambridge University, Cambridge, 2000.

55. Habermas, J.; On the Pragmatics of Communication, Polity, Cambridge, 1998.

Thémata. Revista de Filosofía N 55 (2017) pp.: 83-130. 
saberes científicos, como ahora exige el ideal irrenunciable de una ciencia unificada ${ }^{56}$.

De todos modos, el "nuevo dualismo" de von Wright también quiso ver en "La lógica de la investigación" de Popper un cambio de paradigma en el respectivo marco de cobertura legal. De hecho este paradigma se terminaría materializando en la aceptación del nuevo modelo explicativo-comprensivo de Popper-Hempel-Oppenheim. Es decir, un nuevo modelo de integración entre lo teórico y lo observacional, o entre la explicación y la comprensión. De este modo los dos modelos podrían ampliarse y reformularse, hasta dejarlos prácticamente irreconocibles, sin necesidad de modificar en sus líneas esenciales los dos anteriores modelos antes descritos. En este sentido von Wright opina que el nuevo modelo explicativo-comprensivo de Popper-Hempel-Oppenheim se sigue remitiendo a aquellos tres presupuestos comprensivos básicos que ahora siguen contradistinguiendo a la "La lógica de la investigación", frente a los anteriores rasgos presentes también en el Tractatus ${ }^{57}$, a saber:

a) La aceptación de un pluralismo metodológico comprensivo. Sólo así se podría postular las múltiples formas posibles igualmente validas de interpretación científica de la experiencia, a pesar de también poder refutarse recíprocamente y de poder estar en conflicto recíprocamente entre sís ${ }^{58}$

b) La formulación de un ideal comprensivo de "autoinmunidad" falibilista universal. De hecho este principio obliga a tener que tratar de refutar cualquier proposición científica que pretenda dejar de serlo, salvo que se quiera correr el riesgo de negar indebidamente el carácter científico a quien lo posee. De hecho se trata del procedimiento paradójicamente más adecuado para tratar de alcanzar una comprensión crítica plenamente

56. Por eso ahora afirma Wright: >"Sería totalmente erróneo considerar que la filosofía analítica en su conjunto representa una rama del positivismo. Pero es acertado reconocer que las contribuciones de la filosofía analítica a la metodología y a la filosofía de la ciencia se han mantenido hasta hace bien poco predominantemente fieles al espíritu positivista, si por "positivismo" se entiende una filosofía partidaria del monismo metodológico, de ideales matemáticos de perfección y de una perspectiva teórico-subsuntiva de la explicación científica" $<$. Wright, G. H. von; EU, p. 9; EC, p. 28; Cf. Lenk, H.; Skarica, M.; Wittgenstein und die schema-pragmatische Wende, Argumentaciones, Lit, Münster, 2009.

57. Cook, J. W.; Wittgenstein, Empiricism, and Language, Oxford University, New York, 2000.

58. Wittgenstein, L.; Nedo, M. (Hrsg); Wiener Ausgabe. Studien Texte. B. 1-5, Springer, Wien, 1999.

Thémata. Revista de Filosofía ํ55 (2017) pp.: 83-130. 
compartida, sin que ello impida una posible refutación de estas mismas propuestas $^{59}$;

c) La justificación de un nuevo tipo de comprensión científica que debería ser capaz de subsumir teóricamente las más diversas formalizaciones de la experiencia bajo múltiples formas de cobertura legal diferenciadamente normalizadas, aunque sólo una de ellas debería ser verdaderamente válida. Sin embargo estas diversas formas de comprensión tampoco podrán evitar la ulterior aparición de posibles discrepancias entre ellas, teniéndoles que otorgar en cada caso un valor explicativo específico. ${ }^{60}$

A este respecto von Wright concibe el "nuevo dualismo" post-analítico como el resultado de un tránsito bipolar desde un proyecto programático donde predomina el modelo explicativo estrictamente positivista-lógico de Russell y el primer Wittgenstein hasta otro donde predomina el modelo comprensivo de carácter racionalista crítico de Popper. Sin embargo se reconoce simultáneamente que puede haber muchas situaciones intermedias de equilibrio entre ellos. En este sentido se hace notar la creciente prevalencia que habría seguido ejerciendo el legado dejado por los modelos nomológicos deductivos que aún hoy siguen vigentes en el "nuevo dualismo", manteniendo unas actitudes heurísticas muy definidas, a saber: a) la sobrevaloración del pluralismo metodológico comprensivo frente al monismo explicativo uniformista; b) la exención universal comprensiva falibilista frente a la exención dogmática explicativa inductiva; c) la normalización comprensiva divergente frente a las simples explicaciones puntuales que pueden estar forzadas normativamente. Pero, a pesar de todo, se reconoce la persistencia de esta tendencia hacía una creciente fragmentación metodológica comprensiva, como especialmente se acabaría comprobando en el llamado pensamiento débil o postmoderno. Sin embargo ahora también se quiere extraer un punto de reflexión respecto de los distintos saberes en sí mismos fragmentarios, a saber: en su opinión, también hoy día se debe considerar posible, e incluso necesario, llevar a cabo una efectiva reunificación gradual explicativo-comprensiva entre los distintos saberes, aunque nunca la reunificación podrá ser completa. Sin embargo se trata de una reflexión que ahora se formula respecto de las diversas corrientes meto-

59. Wirth, U.; Die Welt als Zeichen und Hypothese. Perspektiven des semiotischen Pragmatismus von Charles S. Peirce, Suhrkamp, Frankfurt, 2000.

60. Dahms, H-J.; Positivismusstreit, Suhrkamp, Frankfurt, 1994.

Thémata. Revista de Filosofía №55 (2017) pp.: 83-130. 


\section{El legado del positivismo lógico, 50 años después. \\ La autoinmunidad hipercrítica del neodualismo postanalítico}

dológicas post-modernas más extremas, aunque ahora se siga postulando diversos grados de reunificación muy distinta ${ }^{61}$.

\section{2.c. La bipolaridad explicativo-comprensiva del "nuevo dua- lismo" nomológico-deductivo}

Von Wright también señaló una segunda bipolaridad o más bien trilateralidad presente preferentemente en el llamado modelo Popper-Hempel-Oppenheim, a saber: la contraposición que ahora también se establece entre las leyes nomológicas que se siguen justificando en nombre de dos principios antitéticos. Al menos así se comprobó en el caso de Russell y el primer Wittgenstein, a saber: por un lado, un inductivismo explicativo presuntamente exhaustivo y al que se asigna una universalidad aún más estricta. Sin embargo esta propuesta estuvo muy lejos de conseguirlo, como ahora ocurre con la presunta justificación "autoinmune!" del modus ponens; $\mathrm{y}$, por otro lado, un decisionismo comprensivo aún más autocrítico que, como postuló Popper, debería permitir justificar ciertos principios hipotéticos elaborados totalmente de espaldas a la propia experiencia, con tal de admitir la aplicación de un principio de refutación, como ahora ocurriría con la autoinmunidad falibista atribuida al modus tollens. Y, finalmente, la validez de las simples generalizaciones estadísticas, probabilistas, o de cualquier otro tipo. En este caso estas proposiciones también pretenden justificarse en nombre de unas leyes verdaderamente nomológicas universales. Sin embargo deben recurrir a un principio de inducción incompleta verdaderamente falsacionista, sin poder alcanzar a justificar una universalidad estricta, como en principio sería de esperar. Todo ello hace que a estas leyes estadísticas y probabilistas tampoco se le pueda aplicar un principio de verificación, ni tampoco de refutación, por lo que tampoco se las debería considerar leyes propiamente científicas ${ }^{62}$.

En este sentido el "nuevo dualismo" advirtió las limitaciones nomológico-deductivas de las que adolecía el modelo de cobertura legal de

61. En este sentido se afirma: > Asumamos que el estado total del mundo en una ocasión dada puede ser completamente descrito mediante la aserción, para cualquier miembro dado de un estado-ámbito, (con independencia) de si el miembro en cuestión tiene lugar o no lo tiene en la ocasión considerada. Un mundo que satisface esta condición puede ser llamado mundo-Tractatus. Es el tipo de mundo que (el primer) Wittgenstein contemplaba en el Tractatus. Forma parte de una concepción más general sobre la constitución del mundo. Podemos llamar atomismo lógico a esta concepción general”<. Wright, G. H. von; EU, p. 44-45; EC, p. 67-68; Cf. Mitjashin, A.; The World and Language. The Ontology for Natural Language, UPA - University Press of America, Lanham, 2006.

62. Watzka, H.; Sagen und Zeigen. Die Verschränkung von Metaphysik und Spachkritik beim frühen und beim späten Wittgenstein, Kohlhammer, Stuttgart, 2000.

Thémata. Revista de Filosofía Nº55 (2017) pp.: 83-130. 
Popper-Hempel-Oppenheim. Se trataba de una postura que trataba de articular los aciertos del positivismo lógico del primer Witgenstein, con las ventajas racionalismo crítico de Popper, aunque con una diferencia. Pera el positivismo lógico la aceptación de una ley universal exige la previa confirmación de un proceso inductivo generalizador que debería aspirar a lograr una confirmación posterior por parte de todos los posibles afectados, con independencia del grado de confirmación del que inicialmente se tome como punto de partida. Hasta el punto de que toda proposición presuntamente inductiva debe concebirse a si misma como resultado de un dogmatismo inductivo excesivamente universalizador. De hecho ya se sabe de antemano que resulta de imposible comprobación una universalización completa de las proposiciones experimentales singulares que se toman como punto de partida, como entonces se propuso. Por su parte, el modelo Popper-Hempel-Oppenheim concibió la ciencia como un conjunto de leyes refutables a las que se sigue asignando una tenaz "autoinmunidad" comprensiva falibilista frente a cualquier posible oponente, Sólo se exige que momentáneamente o en un futuro consigan evitar una posible refutación. Es más, sería incluso factible en estos casos un ulterior reforzamiento de este inicial proceso de autocomprensión, a pesar de habérseles aplicado el principio de refutación. Especialmente cuando se comprueba la posibilidad de volver a confirmar en una ocasión posterior la explicación de aquellos presupuestos anteriormente dados por provisionalmente refutados. Sin embargo el modelo Popper-Hempel-Oppenheim tampoco pudo renunciar en estos casos al recurso inicial a un cierto dogmatismo explicativo inductivista meramente instrumental, dado que en caso contrario tampoco se podría iniciar este mismo tipo de procesos ${ }^{63}$.

\section{2.d.La“autoinmunidad" explicativo-comprensiva en el "nuevo dualismo"}

De todos modos las discrepancias en el marco del "nuevo dualismo" se incrementarían aún más a la hora de asignar un carácter "autoinmune" explicativo o, por el contrario, comprensivo, a los presupuestos o condiciones de sentido que a su vez hacen posible la formulación de este tipo de

63. A este respecto se afirma: >"El estudio general de los sistemas de control (...) ha tenido una influencia considerable por no decir revolucionaria en la ciencia moderna. Algunos piensan que constituye una (auténtica) contribución científica (...., aunque) al mismo tiempo haya reforzado algunos de los dogmas más importantes de la filosofía de la ciencia, en particular la consideración unitaria del método científico y la teoría de la explicación por subsunción" $<$. Wright, G. H. von; EU, p. 17-18; EC, p. 38; Cf. Ortiz de Landázuri, C.; 'Dos melioristas: ¿Lógica de la justificación o ética de las creencias?', Nubiola, J. (ed); Peirce y Popper. La ética y la lógica de la ciencia, Anuario Filosófico, XXXIV/1, 2001, enero, pp. 75-100.

Thémata. Revista de Filosofía N 55 (2017) pp.: 83-130. 


\section{El legado del positivismo lógico, 50 años después. \\ La autoinmunidad hipercrítica del neodualismo postanalítico}

leyes, ya sea a corto o a largo plazo. En este sentido la "autoinmunidad" inductiva del Tractatus reside siempre en los requisitos o condiciones de sentido que impone la explicación de la propia experiencia a corto plazo. De hecho ya no hay posibilidad de eludirlos o simplemente posponer su valoración indefinidamente. En cambio para el falsacionismo de la Lógica de la investigación popperiana la "autoinmunidad" residiría más bien en la comprensión de aquel término final a largo plazo de esta búsqueda sin término en la que se transforma la investigación científica. Con la circunstancia añadida de que en todo momento esta comprensión o mejor autocomprensión de las propias hipótesis siempre debe quedar sobreentendida, sin efectivamente se pretende que no pueda ser refutada. En este contexto la única operatividad práctica, tanto del principio de inducción del primer Wittgenstein, como del principio de refutación de Popper, consiste en separar dos niveles o tipos de "autoinmunidad"64, a saber:

a) La "autoinmunidad" explicativa condicionada o meramente hipotética. En este caso todos aquellos principios, leyes o teorías que no se pueden justificar en nombre de un principio de inducción estricta, tienen que pasar a ser considerados meras hipótesis abiertas a un proceso de refutación. Por eso hay que atribuirles inicialmente un origen pseudo-inductivo de carácter hipotético o no-científico. Al menos así ocurre en general con el mal uso del lenguaje o con los principios de la metafísica o de la moral, cuya validez en gran parte dependen inicialmente de las decisiones subjetivas de cada individuo, aunque posteriormente se puedan ver confirmados o refutados por la experiencia ${ }^{65}$.

b) La "autoinmunidad" comprensiva incondicionada. En este caso la "autoinmunidad" se refiere a todos aquellos presupuestos que se afirman como una condición de posibilidad y de sentido a corto o largo plazo de la correcta justificación y seguimiento de un principio de inducción o falsación. Al menos así sucede ahora con la aceptación de la existencia de "hechos empíricos" y de las correspondientes "proposiciones protocolarias", o del propio "modus tollens". Pero igualmente ocurre con las nociones más generales de "mundo", incluso de llamado "mundo"-Tractatus, de ley, de "necesidad", etc. De hecho ninguna de estos principios podría justificar aquella específica "autoinmunidad" comprensiva incondicionada que ahora se exige inicialmente al conjunto de las proposiciones científicas, mientras no sean refutadas. Sin embargo es evidente que tampoco se puede

64. Horn, P. R.; Gadamer and Wittgenstein on the Unity of Language: Reality and Discourse Without Metaphysics, Ashgate, Hampshire, 2005.

65. Velleman, J. D.; The Possibility of Practical Reason, Oxford University, Oxford, 2000.

Thémata. Revista de Filosofía N55 (2017) pp.: 83-130. 
prescindir absolutamente de ellas ya que sería considerarlas como parte de la no ciencia ${ }^{66}$.

De todos modos la situación es totalmente distinta a la que se genera en el caso de la "Lógica de la justificación" de Popper. En efecto, en este caso la justificación nomológica-deductiva de las leyes se alcanza a partir de otros principios y teorías más generales. Sin embargo se concibe como una cuestión a largo plazo que cada vez se encuentra más condicionada explicativamente por diversos factores metodológicos que cada vez dependen más del propio uso de la razón crítica. En este contexto la función prioritaria del principio de refutación popperiano sería tratar de distinguir dos tipos de "autoinmunidad"67, a saber:

a) La falsa "autoinmunidad" explicativa, condicionada, hipotética o a corto plazo. Según Popper, se trata de una "autoinmunidad" que pretende afirmarse por si misma a corto plazo sin subordinarse a la subsiguiente aplicación de un principio de refutación. Al menos así ocurre con muchos principios de las metafísicas cerradas, que no aceptan la aplicación de un principio de refutación: Pero ahora esta "autoinmunidad" también se asigna a la mayor parte de los aforismos del Tractatus, que no simpre pueden justificar su origen inductivo. Especialmente los aforismos referidos al ahora denominado mundo-Tractatus por von Wright. En efecto, en su opinión, el primer Wittgenstein impone a su noción de mundo una determinada configuración lógico-lingüística que se afirma como un presupuesto auto-inmune en sí mismo incondicionado de cualquier explicación científica, a pesar de no poderse conocer mediante un proceso inductivo. En este sentido el inductivismo de Wittgenstein exige una descripción puntual lo más fidedigna posible de todos y cada uno de los hechos empíricos o acontecimientos verificables que componen este tipo de nociones máximamente universales. A este respecto se trata de nociones que escapan a la aplicación de un principio de refutación, y simplemente se pueden sobreentender de un modo implícito ${ }^{68}$;

b) La auténtica "autoinmunidad" comprensiva e incondicionada a largo plazo. Según Popper, este tipo de comprensión se puede ver refutada a corto plazo por una explicación de carácter falibilista, a pesar de que nunca se debe dar por vencida; es decir, se debe exigir una nueva reformulación de aquellos mismos principios, reglas y leyes que ahora se

66. Goeres, R.; Die Entwiklung der Philosophie Ludwig Wittgensteins unter besonderer Berücksichtigung seiner Logikkonzeptionen, Königshausen und Neumann, Würzburg, 2000.

67. Rescher, N.; Natura and Understanding. The Metaphysics and Methode of Science, Oxford University, Oxford, 2000.

68. Harris, G. W.; Agent-Centered Morality. An Aristotelian Alternative to Kantian Internalism, California University, Berkeley, 1999.

Thémata. Revista de Filosofía №55 (2017) pp.: 83-130. 
consideran incondicionalmente "autoinmunes" como formando parte de un proceso de comprensión, aunque provisionalmente hayan podido ser refutados. En efecto, en la medida que deben ser justificados ante cualquier posible oponente, tampoco debe haber ningún temor a que puedan ser objeto de un proceso de refutación, si efectivamente se sustituyen por otros mejores que pueden ser aceptados por todos. Hasta el punto que ahora se conciben como principios hermenéuticos estrictamente necesarios para justificar una posible comprensión máximamente universal de este mismo proceso de "autoinmunidad" falibilista. Con el agravante de que, en el caso de pretender negarlos, volverían a resurgir aún más reforzados en sus pretensiones de "autoinmunidad" falibilista cuantas veces hiciera falta. Al menos así sucede con un gran número de conceptos, como la noción de ley, de teoría, de mundo, o de la propia regla del "modus tollens", etc. A este respecto se puede aceptar las ahora denominadas metafísicas abiertas, que se justifican mediante la aplicación aún más universal de un principio de falsación, admitiendo la posibilidad de una refutación, como ocurre con el atomismo o el darwinismo o con la propia teoría de la relatividad ${ }^{69}$.

\section{2.e. El modelo explicativo-comprensivo Popper-Hempel-Oppenheim}

En cualquier caso al "nuevo dualismo" post-analítico de von Wright analizó retrospectivamente estas propuestas 50 años después. Especialmente se tuvo en cuenta el modo como estas tesis se habrían acabado materializando en el modelo Popper-Hempel-Oppenheim, aunque con una novedad: el modelo Popper-Hempel-Oppenheim habría introducido un nuevo modelo integrador de cobertura legal que ahora se afirma como el auténtico fin o telos hacia el que se orienta toda auténtica indagación heurística. En efecto, para el "nuevo dualismo" lo fundamental de este modelo híbrido consiste en su pretensión de hacer compatibles las estrictas exigencias de la explicación y las mayores pretensiones de la comprensión; es decir, admitir estas nuevas formas de minimalismo inductivista cada vez más puntual junto a las máximas pretensiones de "autoinmunidad" falibilista que ahora vienen exigidas a corto y largo plazo por este doble modelo de cobertura legal. Sin embargo estos modelos siguen siendo similares a las propuestas del positivismo lógico de Russell y el primer Wittgenstein,

69. Dowe, P.; Phisical Causation, Cambridge University, Cambridge, 2000.

Thémata. Revista de Filosofía №55 (2017) pp.: 83-130. 
o del racionalismo crítico de Popper, con una doble circunstancia, a saber: la necesidad de remitirse a una doble exigencia irrenunciable ${ }^{70}$.

A este respecto el "nuevo dualismo mantiene una doble dependencia respecto de las propuestas del positivismo lógico, a saber: por un lado, la referencia a unos hechos empíricos y a unas proposiciones atómicas que a su vez se afirman como el punto de partida y de llegada de cualquier proceso explicativo inductivo puntualmente verificador y mínimamente universalista. Hasta el punto de afirmarse como el nuevo rasgo identificador del ideal de las ciencias unificadas; y, por otro lado, la necesidad de presuponer unos esquemas heurísticos o marcos conceptuales reguladores cada vez más amplios donde tendrían cabida los sucesivos procesos hipotéticos de falsación mediante los que se avala o se refuta el logro de una máxima comprensión respecto del mundo entorno que nos rodea. Sólo así se podrá hacer un doble uso aún más crítico de estos mismos marcos conceptuales explicativos y a la vez comprensivos. Con la ventaja añadida de no tener que renunciar a la posibilidad de acercarse aún más a la realidad, a pesar de nunca lograrlo completamente ${ }^{71}$.

En este contexto el "nuevo dualismo" post-analítico siempre trató de salvar las pretensiones explicativas minimalistas de "verificación inductivista" del positivismo lógico, así como las pretensiones comprensivas maximalistas de "autoinmunidad falibilista" del racionalismo crítico. Al menos así se pretendió seguir justificando cualquier proceso de explicación y comprensión científica frente a cualquier posible oponente, con las lógicas limitaciones que en cada caso se generan. Además, el hallazgo de este nuevo tipo de esquemas heurísticos o marcos conceptuales explicativo/ comprensivos habría permitido a Popper introducir, según Wright, una profunda inversión heurística en el anterior modo positivista-lógico de concebir el método inductivo-axiomático de la teoría de la ciencia empirista. En su lugar se habría seguido una estrategia metodológica explicativo-comprensiva muy diferente, a saber: tratar de salvaguardar las correlaciones que ahora se establecen entre las observaciones, las teorías y el lenguaje científico mediante un peculiar doble modelo de cobertura legal, que a su vez adolecería de un doble carácter inductivo y conceptual, explicativo y comprensivo, con una particular virtualidad, a saber: justificar las inducciones puntuales y los procesos de universalización creciente en nombre de estos dos procedimientos contrapuestos ahora descritos. Sólo así podrían aducir un valor igualmente autoinmune, tanto desde un punto de vista

70. Potter, M; Ricketts, T. (eds.), The Cambridge Companion to Frege, Cambridge University Press, Cambridge, 2010.

71. Cabrera, I. (ed); Argumentos transcendentales, UNAM, Instituto Investigaciones Filosóficas, Mexico, 2000.

Thémata. Revista de Filosofía №55 (2017) pp.: 83-130. 


\section{El legado del positivismo lógico, 50 años después. La autoinmunidad hipercrítica del neodualismo postanalítico}

explicativo como comprensivo, analítico como sintético ${ }^{72}$.

Además, el modelo Popper-Hempel-Oppenheim también se acabaría viendo obligado a tener que recurrir al método contrario, contraponiendo sistemáticamente este doble modelo explicativo y a la vez comprensivo. Solo así se podrían diagnosticar y hacer frente a las inevitables insuficiencias y anomalías que cada modelo heurístico pudieran presentar por separado, sin poder ya prescindir de su contrario. De hecho la defensa a ultranza de un inductivismo cada vez más minimalista se acabaría viendo como una de las causas principales del recurso abusivo que con frecuencia en estos casos se siguió haciendo a explicaciones claramente desproporcionadas. Con el agravante de incrementar aún más el mal uso del lenguaje cotidiano, cuando era lo que en gran parte se pretendía evitar. Hasta el punto de verse obligados recurrir a la estrategia contraria a fin de invertir este tipo de procesos claramente abusivos, a saber: comprobar el carácter dogmático de este tipo de procesos inductivos en sí mismos hipertrofiados, salvo que se recurra a la estrategia contraria, a saber: presuponer una posible refutación del propio proceso de comprensión de sus respectivos presupuestos, dado que en ese caso carecería de sentido seguir tratando de explicar sus consecuencias mediante un método inductivo. Al menos así también ahora ocurrirá con la mayor parte de las proposiciones de Tractatus, concibiéndolas como proposiciones explicativas formuladas respecto de un mundo ideal, que a su vez se contrapone al mundo real que efectivamente debería ser objeto de una comprensión recíproca. Solo en una situación de este tipo se podría pretender describir el mínimo explicativo heurísticamente imprescindible que permitiera alcanzar una mejor comprensión, como ahora se pretende. Es más, se podrían incluso concebir estas propuestas como si fueran en sí mismas "autoinmunes" ante toda posible crítica, dado que en ese caso se trataría de principios que deberían estar necesariamente sobrentendidos en todo proceso de explicación experimental, o de comprensión hermenéutica, con independencia de que se logre verificarlos o refutarlos ${ }^{73}$.

Pero algo similar, aunque en sentido contrario, también le acabó sucediendo a la "Lógica de la investigación científica" de Popper. Tam-

72. A este respecto Popper resumió así su visión del problema: >”Brevemente expuesto, mi punto de vista es que nuestro lenguaje habitual está lleno de teorías, que llevamos a cabo toda observación a la luz de teorías, que el prejuicio inductivista es el único que lleva a muchos a creer que podría existir un lenguaje fenoménico, libre de teorías y distinguible de un "lenguaje teórico"; y, finalmente, que el teórico se interesa por la explicación como tal, es decir por las teorías explicativas contrastables: las aplicaciones y las predicciones le interesan solamente por razones teóricas - porque pueden emplearse como medios para construir teorías _“<. Popper, K.; LF, p. 31; LSD, p. 59; LIC, p. 57, nota 1. Cf. Hinterberger, N.; Der Kritische Rationalismus und seine Antirealistischen Gegner, Rodopi, Amsterdam, 1996.

73. A este respecto afirma Wright: >"El segundo procedimiento (popperiano) nos coloca frente

Thémata. Revista de Filosofía $\mathrm{N}^{\circ} 55$ (2017) pp.: 83-130. 
bién en su caso habría defendido una forma peculiar de convencionalismo crítico mediante el que se espera poder salvaguardar la efectiva "autoinmunidad" falibilista de las propuestas metodológicas comprensivas del racionalismo-crítico frente a todo posible oponente; es decir, se habría pretendido justificar así la "autoinmunidad" comprensiva de aquellos esquemas heurísticos o marcos conceptuales que hace posible la investigación científica, saliendo incluso más reforzados respecto de los sucesivos procesos de refutación, a pesar de tener un riesgo evidente: el inconveniente de ir acumulando fracaso tras fracaso, sin poder ya ofrecer en un determinado momento algún éxito efectivo, que confirme el estar en la senda heurística adecuada, salvo que también ahora se recurra a la estrategia contraria, a saber: justificar esta necesidad de tener que seguir aspirando a una universalidad y diversificación heurística cada vez más amplia en nombre de un minimalismo inductivista pluralista aún más fragmentado respecto de lo que hasta entonces sólo se ha comprendido hipotéticamente. Hasta el punto que ahora este pluralismo inductivista explicativo se afirma como una condición de posibilidad y de sentido de la creciente pretensión por alcanzar una mejor compresión de los distintos ámbitos del saber. De hecho sería imposible dejar de seguir aspirando a un ideal tan elevado de una justificación de todas las ciencias, a pesar de los iniciales resultados tan aparentemente derrotistas y escépticas ${ }^{74}$.

$\mathrm{Al}$ menos así habría ocurrido con la propia noción de ley física o natural, o de teoría científica experimental, o de lenguaje protocolario, a pesar de los abundantes fracasos obtenidos en sus aplicaciones prácticas. En efecto, en el caso de poder ser refutados en algunas de sus aplicaciones concretas, nunca se debe inferir que se trata de nociones falsas, mal formalizadas, anticuadas o necesitadas de una puesta al día heurística. Más bien se debería concluir que hay que hacer un uso de ellas máximamente diversificado y pluralista de los respectivos procesos de comprensión hermenéutica. Sólo así se evitará quedar anclados en modos de aplicación que son más propios de otros paradigmas de otras épocas, aunque para ello se deben cumplir a su vez con dos condiciones, a saber: a) respetar el mínimo inductivo explicativo que ahora exige de un modo crítico-transcendental el logro de una efectiva

a un punto de vista sobre las leyes naturales que podría tomarse como alternativo al punto de vista positivista clásico. De acuerdo con esta concepción alternativa, una ley puede resultar inmune a la refutación empírica en virtud de su estatuto de verdad analítica, lógica. La conformidad con la ley viene a ser entonces una pauta de identificación con arreglo a la cual se clasifican los casos individuales en calidad de incluidos o no incluidos en el conjunto de fenómenos contemplados por la ley. Todo A es B, de modo que si algo pretende ser A y resulta no ser B, entonces tampoco resulta ser A a fin de cuentas<. Wright, G. H. von; EU, p. 19-20; EC, p. 40; Cf. Chiffi, D.; Minazzi, F. (eds); Riflessioni critiche su Popper, Franco Angeli, Milano, 2005.

74. Wright, G. H. von; EU, p. 20; EC, p. 40; Cf. Tugendhat, E.; The hermeneutic nature of Analytic Philosophy, Zabala, S. (ed.); Columbia University, New York, 2008.

Thémata. Revista de Filosofía N55 (2017) pp.: 83-130. 


\section{El legado del positivismo lógico, 50 años después. \\ La autoinmunidad hipercrítica del neodualismo postanalítico}

verificación experimental. De hecho se afirma como una condición de posibilidad y de sentido que ahora viene exigida por la propia comunicación científica; y b) localizar un esquema heurístico o marco conceptual que permita alcanzar la máxima comprensión de la correspondiente investigación científica en los más diversificados ámbitos del saber ${ }^{75}$.

En cualquier caso las sucesivas refutaciones que se pretendan poner en práctica deben suponer necesariamente un debilitamiento de su propia validez interna. En su lugar más bien debería conllevar un reforzamiento en su pretensión por lograr una progresiva adecuación a un determinado estado de cosas. Sólo así se pudo otorgar a los correspondientes hechos, conceptos y proposiciones científicas una mínima "universalidad inductiva" y una máxima "autoinmunidad falibilista" cada vez más abierta al resto de los saberes. Hasta el punto de poder dar entrada a un doble proceso de puntual consolidación inductiva y de indiscriminada refutación ilimitadamente ampliable. Es más, incluso podría darse el caso de haber salido reiteradamente reforzados o debilitados de la prueba de la inducción o de la refutación. Pero, incluso entonces, también en esos casos siempre sería posible alcanzar una reformulación aún más diversificada y amplia, y en definitiva, más "autoinmune" de esas mismas nociones. Hasta el punto que ahora se atribuye a estas nociones la exigencia irrenunciable de adolecer de un minimalismo explicativo inductivo y de un maximalismo comprensivo autoinmune ante toda posible crítica. En efecto, siempre será posible encontrar en estos casos unas aplicaciones heurísticas cada vez más diversificadas y amplias respecto de estos modelos de cobertura legal, aunque previamente hayan podido dar lugar a muchas extralimitaciones y refutaciones que se hubieran podido evitar. Pero pasemos ahora a ver lo que afirma Apel al respecto ${ }^{76}$.

\section{Apel, 1979: La autoinmunidad pragmático-transcendental del "nuevo dualismo".}

Apel revisó las propuestas de von Wright, en La controversia explicación y comprensión (1979). Posteriormente ha profundizado este tipo de propuestas

75. Houser, N.; et alia (eds); Studies in the Logic of Charles Sanders Peirce, Indiana University, 1997.

76. A este respecto Popper había afirmado: >"Creo, sin embargo, que la idea de que haya leyes necesarias en la Naturaleza, (...) tiene importancia metafísica u ontológica, y un gran significado intuitivo en relación a nuestras tentativas por comprender el mundo. (...) Mas trato actualmente de ir más allá de lo que dije en tales apartados, (...) subrayando el carácter metafísico - o la irrefutabilidad - de la aserción de que las leyes de la Naturaleza existan, no tienen por qué impedirnos discutir dicha aserción de un modo racional"<. Popper, K.; LF, p. 392-393; LSD, p.

Thémata. Revista de Filosofía N55 (2017) pp.: 83-130. 
en una obra más tardía de 1998, Discrepancias a favor de unas prolongaciones pragmático-transcendentales -AETPA- ${ }^{77}$. En ambos casos Apel comparte la reconstrucción de los hechos históricos del pasado propuesta por von Wright. Sin embargo discrepa respecto del sentido final que a su modo de ver se le debe otorgar a estos procesos. En cualquier caso von Wright y Apel llegaron a conclusiones bastante diferentes respecto del legado que hoy día habría dejado la alianza establecida entre el positivismo lógico y el consiguiente falsacionismo o racionalismo crítico. En este contexto Apel habría llevado a cabo una segunda reinterpretación del anterior debate que inicialmente Wright reconstruyó, sin separar los procesos de explicación y comprensión, sino considerándolos parte de un mismo proceso, A este respeto Apel acepta, por un lado, las inevitables explicaciones inductivistas cada vez más puntuales que hoy día sigue reivindicando el método heurístico de los seguidores del primer Wittgenstein; y, por otro lado, denuncia la desproporcionada "autoinmunidad" falibilista cada vez más amplia y diversificada que por su parte reclaman las propuestas post-popperianas ${ }^{78}$.

A este respecto Apel también acabará aceptando un similar uso heurístico de ambos métodos, aunque estableciendo una articulación más estricta entre ellos. A este respecto Apel discrepa de la convergencia resultante que, según Wright, se habría acabado introduciendo entre Wittgenstein y Popper, como si a ninguna de ambas se hubiera visto afectada por este proceso. En efecto, según Apel, como consecuencia de este proceso se habría acabado abriendo paso un modelo nomológico-deductivo de cobertura legal, o el ahora denominado modelo Popper-Hempel-Oppenheim, sin que ninguna ciencia se haya podido quedar al margen. De ahí que ahora en su lugar se proponga más bien el recurso a un nuevo paradigma pragmático-transcendental que a su vez mantiene una complementariedad entre todas las posibles formas de explicación inductiva refutadora y de "autoinmunidad" comprensiva falibilista, sin establecer escisiones artificiales entre ellas. Se admitirá así la articulación interna existente entre ellas, a

438; LIC, p. 409. Cf. Inwagen, P. van; Zimmerman, D. W. (ed); Metaphysics: The Big Questions, Blackwell, Oxford, 1998.

77. Cf. Apel,K-O; Auseinandersetzungen in Erprobung des transzendentalpragmatischen Ansatzes, Suhrkamp, Frankfurt, 1998.

78. Potter, M.; Wittgenstein's Notes on Logic, Oxford University, Oxford, 2009.

Thémata. Revista de Filosofía N55 (2017) pp.: 83-130. 


\section{El legado del positivismo lógico, 50 años después. \\ La autoinmunidad hipercrítica del neodualismo postanalítico}

pesar de las tensiones puntuales que puedan surgir, tratando de integrarlas de un modo pragmático transcendental ${ }^{79}$.

\section{3.a. La triple "autoinmunidad" explicativo-comprensiva del modelo Popper-Hempel-Oppenheim:}

Apel defiende la existencia de un triple modo de integrar los modelos cobertura legal y de "autoinmunidad" propuestos anteriormente por von Wright. Sin embargo tampoco recurre a un único modelo ideal perfecto que sea igual para todas las ciencias. A este respecto Apel discrepa respecto del modelo nomológico-deductivo de cobertura legal propuesto por el "nuevo dualismo" de von Wright, cuando no hay ninguna necesidad de escindir los procesos de explicación y de compresión de forma tan acentuada. En su opinión, el modelo de cobertura legal de Popper-Hempel-Oppenheim no persigue solamente una superposición sobrevenida entre las propuestas inductivo-explicativas iniciales del Tractatus y de las propuestas falsacionistas-comprensivas de La lógica de la investigación científica de Popper. En su opinión, este tipo de propuestas sólo pretenden justificar una continuidad muy superficial entre el programa de la ciencia unificada del positivismo lógico y el pluralismo metodológico de los planteamientos racionalistas críticos post-popperianos, cuando en ambos casos se mueven por motivaciones complementarias distintas ${ }^{80}$.

En cualquier caso Apel opina que von Wright unifica precipitadamente tres modelos de cobertura legal muy diferenciados, cuando existen otras formas mas claras de correlacionar sus respectivos modos de entender la explicación experimental y la comprensión recíproca. Por eso opina que se debe seguir asignando a cada modelo su correspondiente ámbito de anormalidad o disonancia explicativa y de "autoinmunidad" comprensiva, sin tampoco pretender establecer una igualdad mimética entre todos ellos. A este respecto se establece una diferencia entre tres modelos explicativos-comprensivos de cobertura legal, que habría que contraponer a los tres modelos explicativos-comprensivos, ya señalados anteriormente por Wright $^{81}$, a saber:

a) El modelo explicativo-comprensivo de inducción fragmentaria y de "autoinmunidad" falsacionista. Se trata de la interpretación raciona-

79. Demirovic, A.; Der nonkonformistischen Intellektuelle. Die Entwicklung der kritischen Theorie zur Frankfurter Schule, Suhrkamp, Frankfurt, 1999.

80. Hookway, C.; Truth, Rationality and Pragmatism. Themes from Peirce, Clarendon, Oxford University, 2000.

81. A este respecto Apel opina: >"Como punto de partida decisivo para la segunda fase de

Thémata. Revista de Filosofía $\mathrm{N}^{\circ} 55$ (2017) pp.: 83-130. 
lista crítica del modelo Popper-Hempel-Oppenheim que, según Apel, no habría sido correctamente interpretada por von Wright. En efecto, mediante el método de la falsación o refutación de hipótesis el "nuevo dualismo" post-analítico no trató de conseguir simplemente una multiplicidad de puntos de vista heurísticos cada vez más diferenciados y mutuamente contrapuestos entre sí, como von Wright pretende que siga sucediendo en el método explicativo de inducción fragmentaria. Por el contrario, ahora el método comprensivo falsacionista se deben elevar hasta un punto de vista crítico-transcendental, o más bien pragmático-transcendental aún más alto, que exige introducir una posterior articulación diferente de aquella previa multiplicidad de posibles modelos explicativos de tipo semiótico, o incluso metodológico, que von Wright había postulado. De este modo lo que en el Tractatus se concebía como la única base explicativa de aplicación posible, ahora habría quedado abierta a múltiples interpretaciones comprensivas, susceptibles a su vez de una posible refutación y de una sustitución por otra interpretación diferente, a pesar de que la base empírica explicativa podría seguir siendo prácticamente la misma ${ }^{82}$.

b) El modelo explicativo-comprensivo de la "autoinmunidad" crítico-transcendental o más bien semiótico-transcendental. Se trata de una posible versión falsacionista que también se hace presente en el modelo de Popper-Hempel-Oppenheim, ya tenga una génesis positivista o estrictamente analítica. En efecto, ya se intente justificar la validez de un método inductivo explicativo basado en la existencia de una serie casuística de hechos empíricos o ya se intente explicar un conjunto de proposiciones atómicas basadas en una larga cadena lógica de razonamientos consecutivos,

la controversia explicación-comprensión se sitúa a lo largo del siglo 20 el recurso al modelo nomológico-deductivo de explicación causal (modelo DN) de Karl Popper, Gustav Hempel y Paul Oppenheim que debe ser entendido en estrecha conexión al menos con el programa de la "ciencia unificada" o a la "unidad de método" del neopositivismo"<. APEL, K. O.; EVKTPS, p. 44; Cf. Misak, C. (ed.); New Pragmatists, Clarendon, Oxford University, Oxford, 2007.

82. A este respecto Apel afirma: >"Se puede reconocer como un hecho incuestionable que el programa reduccionista de la "ciencia unificada" del neopositivismo permaneció desde un principio como el paradigma de la ciencia natural que a su vez estaba sobreentendido tras la pretensión formal de tipo reduccionista del modelo de Popper-Hempel-Oppenheim, cuando menos en una línea similar al reduccionismo propugnado en un sentido material por el "fisicalismo" del lenguaje científico. De ahí que como representante de las pretensiones de autonomía metodológica de las ciencias de la cultura ("Geiteswissenschaften") quisiera señalar las consecuencias que dicho modelo puede tener (...) en el sentido específico de la comprensión de las reglas o normas, o los motivos en cuanto fundamento de las acciones - por no referirme al sentido hermenéuticamente mediado de los actos de habla, de los textos, de las obras de arte, etc."<. APEL, K. O.; EVKTPS, p. 81; Cf. Krämer, S.; Sprache, Sprechakt, Kommunikation. Sprachtheoretische Positionen des 20. Jahrhunderts, Suhrkamp, Frankfurt, 2001. 


\section{El legado del positivismo lógico, 50 años después. \\ La autoinmunidad hipercrítica del neodualismo postanalítico}

en ambos casos hay un punto de convergencia, a saber; la necesidad de presuponer unas condiciones de posibilidad y de sentido muy precisas; es decir, sigue siendo necesario remitirse a un método crítico-transcendental o semiótico-transcendental que permita elevar el pensamiento explicativo analítico a un nivel de máxima reflexión heurística, ya se interprete desde Kant, Hegel o desde Peirce, como ahora propone Apel ${ }^{83}$.

En cualquier caso Apel opina que Popper, al igual que después von Wright, siguieron haciendo un uso preferentemente "cientifista" del modelo nomológico-deductivo que tanto Wittgenstein, como Popper, Hempel y Oppenheim, introdujeron en la teoría de la explicación y de la comprensión científica, aunque en cada caso se formulara desde presupuestos crítico-transcendentales muy diferentes. Sin embargo, en su opinión, no se acabaron de extraer todas las virtualidades que el método explicativo-comprensivo ahora propugnado por Popper, Hempel y Oppenheim podía haber reportado a las ciencias humanas y sociales. De hecho no terminaron de apreciar que ambos métodos, el científico y el humanístico, se mueven a diversos niveles de argumentación, pero parten de presupuestos similares. Por eso también son susceptibles de diversos tipos de articulación, sin necesidad de concebir el modelo nomológico deductivo de cobertura legal como el resultado de una simple superposición sobrevenida de suyo irreflexiva entre métodos en sí mismos heterogéneos ${ }^{84}$.

c) El modelo explicativo-comprensivo de la "autoinmunidad" pragmático-transcendental peirceana que también estaría sobreentendido en el anterior modelo de Popper-Hempel-Oppenheim ${ }^{85}$. En efecto, ya se tome un punto de partida explicativo inductivista o positivista lógico, o un punto de partida comprensivo, falsacionaslista o racionalista crítico, en cualquier caso siempre hay un punto en común: la necesidad de postular una meta u objetivo final que debería estar sobreentendido en ambos métodos desde un principio. Especialmente si se pretende justificar su articulación interna posterior, sin introducir una mera yuxtaposición extrínseca entre ellos. En efecto, según Apel, el mero seguimiento de un método explicativo inductivo o de un método comprensivo de la falsación o de refutación de hipótesis, ya exige aceptar una articulación interna entre ambos métodos heurísticos ${ }^{86}$.

Pero igualmente también presupone el reconocimiento de la ilimitada distancia de tipo pragmático-transcendental que ahora se establece

83. Hookway, Peirce, Routledge and Kegan Paul, London, 1985.

84. Brent, J.; Charles Sanders Peirce. A Life, Indiana University, Bloomington, 1998.

85. K. Oehler, Charles Sanders Peirce, C.H. Beck, München, 1993.

86. K.L. Ketner, Peirce and Contemporary Thought. Philosophical Inquiries, Fordham University Press, New York, 1995.

Thémata. Revista de Filosofía N55 (2017) pp.: 83-130. 
entre ambos modos de acceder al "mundo". Lo cual sólo se podrá aceptar, siempre que posteriormente se establezca una separación aún más precisa entre la distinta forma de concebir el "mundo", a saber; o bien se concibe el "mundo" cómo resultado de una serie inductiva explicativa que cuando se proyecta en el futuro siempre acabará siendo parcial, al modo como ocurrió en el mundo empírico de Hume; o bien se concibe el "mundo" como resultado de una simple "autorregulación" comprensiva operada de un modo normativo por nosotros mismos. Al menos así ocurrió en los "mundos éticos normativos" de Kant; o en los "mundos históricos culturales" Hegel, como consecuencia de la recíproca coacción compartida ejercida por el "mundo social" y el "mundo cosmopolita"; o también en la propia noción de "realidad compartida" de Peirce. Especialmente cuando se concibe la "realidad" como el resultado de una doble proyección inductiva e ilimitadamente universal "a largo plazo" de dos factores, a saber: por un lado, el mundo real fragmentariamente conocido; y, por otro lado, la "opinión final" resultante de la integranción de ambos procesos explicativo-comprensivos, como ahora también propone Apel $^{87}$.

\section{3.b. La inevitable falacia cientifista del modelo Popper-Hem- pel-Oppenheim}

De todos modos la desvinculación que ahora se propone entre las tres anteriores estrategias de "autoinmunización" explicativa-comprensi$v a$ también genera dificultades evidentes, tanto desde un punto de vista especulativo como práctico. A este respecto Apel también denunció la aparición en el "nuevo dualismo" post-analítico de la llamada paradoja cientifista que se produce en el caso de que el modelo nomológico deductivo

87. A este respecto Apel afirma: >"Precisamente y en referencia a La lógica de la investigación científica de Popper se debe decir esto: También cuando nosotros no podemos verificar válidamente una ley causal de una ciencia natural, y sin embargo debemos sopesar la posibilidad de una falsificación, (...) ya estamos presuponiendo una diferencia pragmático-transcendental respecto de los conceptos generales meramente empíricos de las correspondientes ciencia naturales. Este es el marco desde el que se formula la pregunta (acerca de la validez de la ley), que nunca se puede confirmar (corroborar) a través de la regularidad de una ley causal empírica. (...) A este respecto Popper modificó el punto de vista de la ley causal empírica desde dentro de sí misma mediante una defensa meramente lógica (del papel desempeñado) por las representaciones empíricas de la inducción. (...) En este sentido se puede también decir con C. S. Peirce, que la validez metodológica de una comprobación inductiva "a largo plazo" de una ley causal a través del cultivo de las facultades de control práctico-técnico sobre la naturaleza, siempre está implícita en el marco pragmático-transcendental de la realización de una acción experimental"<. APEL, K. O.; EVKTPS, p. 136-137. Cf. Wegerhoff, T.; Hegels Dialectik. Eine Theorie der positionalen Differenz, Vandenhoeck und Ruprecht, Göttingen, 2008.

Thémata. Revista de Filosofía N55 (2017) pp.: 83-130. 


\section{El legado del positivismo lógico, 50 años después. \\ La autoinmunidad hipercrítica del neodualismo postanalítico}

pretendiera seguir articulando los respectivos métodos inductivos universalistas y a la vez "autoinmunes falibilistas". En estos casos se generaría una mera superposición sobrevenida entre la explicación y la subsiguiente comprensión, cuando en realidad se pueden establecer una relaciones muy distintas. En efecto, en el caso de que los tres modelos pretendieran estar internamente articulados, bastaría que uno de ellos se desarticulase y pretendiera afirmar su supremacía, para que automáticamente los otros dos perdieran su pretendida "autoinmunidad", ya sea explicativa o comprensiva, dada la imposibilidad de que este tipo de estrategias tan contrarias puedan sobreponerse respecto de la otras ${ }^{88}$.

En efecto, si cada método no lograra mantener una adecuada articulación interna respecto de su contrario, tampoco se podrían contrarrestar una posible extralimitación inductiva o simplemente autoinmunizadora recurriendo de la estrategia contraria. De hecho, en estos casos, ni se podría justificar su carácter inductivo, ni su recíproca autoinmunidad, sino que ambos deberían reconocer el fracaso de la estrategia en cada caso seguida. Hasta el punto que ahora tampoco se puede cambiar su respectiva base inductiva, ni ser refutados, atribuyéndoles otra forma de explicación o una nueva autoinmunidad comprensiva. Es decir, no se podría evitar que en esos casos se acabe produciendo un salto o paso indebido de un extremo a otro de la relación. Al menos así acabó ocurriendo en la falacia naturalista, cuando se dio un paso indebido del "ser" al "debe", aunque con una diferencia: ahora se produciría un salto o paso indebido desde una explicación inductiva meramente hipotética a una "autoinmunidad" falibilista comprensiva en sí misma incondicionada, o viceversa, sin poder evitar la aparición de una falacia cientifista. Es decir, se acabaría recurriendo al análisis pseudo-inductivo de las relaciones miméticas que de un modo fáctico la explicaciones heurísticas establecen entre el respectivo sujeto-objeto, con un objetivo muy preciso, a saber: justificar a su vez las peculiares relaciones pseudo-convencionales que el método de la falsación o de la refutación de hipótesis introduce a su vez en los respectivos procesos de comprensión entre las respectivas relaciones sujeto-objeto-cosujeto, cuando en realidad se trata de dos niveles de argumentación recíprocamente articulados, pero específicamente distintos ${ }^{89}$.

En cualquier caso la localización de la falacia cientifista permitió comprobar la distinta forma de operar del método positivista o inductivista de la explicación científica en el Tractatus respecto del correspondiente

88. Potter, M.; Reason's Nearest Kin. Philosophies of Arithmetic from Kant to Carnap, Oxford University, Oxford, 2000.

89. Lepore, E.; Meaning and Argument. An Introduction to Logic through Language, Blackwell, Oxford, 2000.

Thémata. Revista de Filosofía Nº5 (2017) pp.: 83-130. 
método de la falsación o refutación de los procesos de comprensión de hipótesis en Popper. En cualquier caso se permitió la entrada de una posible forma se contrarrestar la posible aparición de esta misma falacia, aunque unida al reconocimiento de la imposibilidad de evitarla totalmente ${ }^{90}$.

\section{3.c. El difícil tránsito explicativo-comprensivo hasta una "autoinmunidad" pragmático-transcendental}

De todos modos hay un segundo riesgo aún más difícil de contrarrestar. Se trata de la pretensión de justificar un tránsito explicativo-comprensivo desde un pseudo-universalismo inductivista" presuntamente explicativo hasta una "autoinmunidad" falibilista comprensiva verdaderamente pragmático-transcendental, donde efectivamente se alcance un "consensus omnium" de todos los posibles afectados. Es decir, un tránsito que a su vez se pretende justificar en virtud de una base de aplicación parcialmente inductiva, mediante la que se pretende justificar a su vez una "autoinmunidad" universal meramente falibilista, a pesar de que por ninguno de ambos procedimientos sea posible garantizar el logro de la meta pragmático-transcendental que se pretende alcanzar. Al menos así sucede ahora con la exigencia de aceptar un "consenso universal" aún más compartido, que ahora postula Apel como meta final incondicionada de este tipo de proyectos programáticos del "nuevo dualismo" post-analítico. Máxime cuando siempre cabe el riesgo de que aparezca un simple hecho que refute este tránsito o la ampliación hacia este horizontes cada vez más desproporcionado al que se aspira ${ }^{91}$.

Evidentemente siempre se puede postular una desarticulación de estos tres procedimientos de explicación consecuencialista y de su corres-

90. A este respecto Apel afirma respecto del método inductivista del "Tractatus", comparando su propuesta respecto a la posterior teoría de los juegos del lenguaje del segundo Wittgenstein: >"Se presenta como posible y también como necesario liberar al concepto de ciencia de una limitación "cientifista", con vistas a otorgarle en su lugar un fundamento normativo que permita dar una respuesta metódica disciplinada a la pregunta humana fundamental acerca de la elaboración del propio conocimiento en el marco de una defendible prolongación pragmático transcendental de la teoría de la ciencia. (...) La falacia cientifista se genera así cuando se lleva a cabo en el marco del juego del lenguaje de la comprensión comunicativa un paso incorrecto donde se considera que el habla en primera y segunda persona se debe poner a un nivel de igualdad que un posible habla respecto de terceras personas, con la aceptación del consiguiente tránsito desde el punto de vista de la observación hasta el de la objetivación teórica respecto de los otros y respecto de la consiguiente explicación de sus acciones"<. APEL, K. O.; EVKTPS, p. 278. Cf. Pippin, R. B.; Hegel's Practical Philosophy. Rational Agency as Ethical Life, Cambridge University, Cambridge, 2008.

91. Müller-Doohm, S.; Das Interesse der Vernunft. Ruckblicke auf das Werk von Jürgen Habermas seit 'Erkenntnis und Interesse', Suhrkamp, Frankfurt, 2000.

Thémata. Revista de Filosofía N 55 (2017) pp.: 83-130. 


\section{El legado del positivismo lógico, 50 años después. La autoinmunidad hipercrítica del neodualismo postanalítico}

pondiente auto-inmunización comprensiva falibilista. Sólo bastaría con que cada modelo tratase de valerse por sí mismo, sin tratar de introducir diversas estrategias de compensación entre ellos. En este sentido siempre cabe la posibilidad de dar entrada a otras formas posibles de verificación o falsación más sutiles, que a su vez permitiesen dotar a las leyes de la naturaleza de sucesivas formas de explicación o de comprensión. Hasta el punto de ya no tener que recurrir a estrategias explicativas o de comprensivas complementaria, que sólo servirían para incrementar aún más las dificultades encontradas. Al menos así podría suceder, según Apel, con la noción popperiana de legalidades probables, a las que ahora también se les atribuye una progresiva capacidad explicativa, así como una creciente autoinmunidad comprensiva ante toda posible crítica, Sin embargo ello obligaría a tener que situar a las leyes científicas en una disyuntiva muy artificial, a saber: o bien alcanzan una plena confirmación inductiva al cien por cien, o aceptan una plena refutación falsacionista que afectara a todos los casos posibles, como hasta ahora había sucedido. Sin embargo Apel opina que siempre caben otras alternativas intermedias posibles ${ }^{92}$.

En efecto, el recurso a una legalidad meramente probable ya no tiene el peligro de provocar un paso indebido de la primera a la tercera persona, como antes ocurría con la legalidad nomológica del positivismo inductivista. De hecho siempre es posible postular por parte de la razón humana una capacidad de dotarse de una especie de segunda naturaleza o de unos hábitos epistémicos aún más sofisticados, que apliquen dicha legalidad según los casos considerados. Sólo así sería posible irse progresivamente adaptando a este nuevo tipo de exigencias, sin pretender explicar la peculiar racionalidad interactiva de las acciones humanas mediante una simple relación mimética con la naturaleza, cuando de hecho se legitiman en nombre de leyes meramente probabilistas ${ }^{93}$.

Apel atribuye así al modelo nomológico-deductivo resultante una explicación inductiva y una autoinmunidad comprensiva falibilista de tipo

92. Stern, R.; Transcendental Arguments and Scepticism. Answering Question of Justification, Oxford University, Oxford, 2000.

93. A este respecto Apel afirma: >"En cualquier caso la noción de legalidad causal (popperiana) se debería poder liberar mediante la noción de legalidad probable, sin que por ello este cambio tenga que afectar de un modo esencial a la posterior aparición de la paradoja del cientifismo. En efecto, se puede aceptar que las leyes probabilistas del comportamiento deben ser compatibles a su vez con la libertad de decisión en un caso particular, a pesar de que las leyes universales contingentes no se puedan conciliar con la auténtica conducta innovadora al modo como exige una ciencia verdaderamente progresiva - que a su vez se enmarca en el contexto del peculiar progreso histórico-cultural de la humanidad. En efecto, en la medida que la intencionalidad de una acción humana bien fundada no puede ser correctamente comprendida en la perspectiva del caso límite de una predisposición, de igual modo que tampoco es posible la explicación de un comportamiento humano a partir de simples leyes probabi-

Thémata. Revista de Filosofía $\mathrm{N}^{\circ} 55$ (2017) pp.: 83-130. 
pragmático-transcendental. En efecto, esta sería la única respuesta posible una vez que las pretensiones conciliadoras de von Wright no hayan obtenido los resultaos esperados. Especialmente por seguir concibiendo por separado los tres protagonistas heurísticos de este proceso, a saber: el método inductivo explicativo, el falsacionismo comprensivo, y su posterior articulación mediante unos juegos del lenguaje cada vez más diversificados y pluralistas. Sin embargo ahora Apel opina que no ocurriría así en el caso de enmarcarse estos tres métodos o procedimientos en una arquitectónica pragmático-transcendental que fuera verdaderamente capaz de autojustificarse frente a toda posible crítica. Con la circunstancia añadida de que esta arquitectónica pragmático-transcendental ahora se concibe como una transformación de los tres niveles argumentativos de tipo fenoménico, transcendental y estrictamente ético o simplemente cívico que ya habían sido señalados por Kant ${ }^{94}$.

\section{4.- Conclusión: ¿Qué destino se puede esperar para el posi- tivismo lógico?}

Evidentemente el destino del positivismo lógico siguió ligado a una determinada visión de la ciencia y de la filosofía en gran parte hoy superada. Sin embargo no por ello ha dejado de ofrecer nuevos horizontes de desarrollo en gran parte insospechados. A este respecto no sería la primera vez que una metodología aparentemente abandonada, volviera a resurgir de sus cenizas, haciendo propuestas que resultan de gran atractivo, si no para el gran público, al menos para el especialista académico. En este sentido, ¿qué destino cabe esperar del legado del positivismo lógico? Podría parecer una pregunta retórica al estilo kantiano, pero no lo es. De hecho a lo largo de estos últimos

listas"<. APEL, K. O.; EVKTPS, p. 252. Cf. Bailey, R.; Education in the Open Society - Karl Popper and Schooling, Ashgate, Aldershot, 2001.

94. A este respecto Apel afirma, detectando el nivel argumentativo ético sobre el que se acabaría centrando el posterior debate explicación-comprensión: >"El sentido de una reflexión pragmático-transcendental acerca de las ya anticuadas condiciones subjetivas del conocimiento, comienza poniendo la mirada en una simplificada "arquitectónica" de la problemática global de la ya mencionada filosofía transcendental de Kant. Desde este punto de vista la "arquitectónica" kantiana separara entre tres ámbitos de conocimiento: 1.- El simple ámbito fenoménico de los procesos naturales; 2.- El ámbito transcendental meramente reflexivo de las "acciones (auto)-comprensivas del yo, en el sentido de la síntesis de la apercepción; y 3.- El ámbito incognoscible, pero "inteligible", de las acciones libres, que a su vez es tematizado de un modo diferenciado por la ética, pudiéndose tomar la libertad de introducir una separación fundamental entre (lo explicable y lo comprensible), es decir, entre el mundo conocible de la legalidad natural y, por otro lado, el mundo conocido en relación a la racionalidad práctica (y de la moral)" $<$. APEL, K. O.; EVKTPS, p. 109-110. Cf. Pippin, R. B.; The Persistence of Subjectivity on the Kantian Aftermath, Cambridge University, Cambridge, 2005.

Thémata. Revista de Filosofía №55 (2017) pp.: 83-130. 


\section{El legado del positivismo lógico, 50 años después. \\ La autoinmunidad hipercrítica del neodualismo postanalítico}

cincuenta años las recientes corrientes analíticas posteriores a las propuestas de von Wright y de Apel han vuelto a retomar las propuestas de "nuevo dualismo" post-analítico en dos orientaciones muy diferentes: o bien han tratado de abordar los nuevos problemas que hoy día presentan las relaciones mente-cerebro en la neurociencia desde este nuevo modelo explicativo-comprensivo de cobertura legal, como ahora se enfatiza a partir de Landesmann y Wright. Así al menos ha sucedido en Dennett. Searle, Lakoff. Churchland. Damasio o Stump, por sólo citar los más conocidos ${ }^{95}$; o bien comprobar como las posturas analíticas se han vuelto a replantear los planteamientos critico-transcendentales que se hicieron presentes en el debate explicación-comprensión en el contexto de la filosofía post-kantiana y post-henegeliana, con problemáticas muy similares, como ahora enfatiza principalmente Apel. Al menos así ha sucedido en los casos de McDowell, Pippin, Elderidge, Alzahuer y Kreines. Máxime cuando ahora se tratan de desactivar las tendencias de tipo oracular y ficcional que ya en su momento fueron denunciadas por Wittgenstein y Popper, y posteriormente aún más por von Wright y Apel ${ }^{96}$.

De todos modos hubo una diferencia importante, entre lo que sucedió entonces, y lo que ha venido ocurriendo en estos últimos 50 años a partir de entonces. Las tendencias metodológicas actuales post-analíticas no pretenden tanto denunciar la presencia de este tipo de unilateralidades de tipo analítico o sintético en una determinada metodología del saber científico, como introducir un profundo cambio en el modo de abordar este tipo de problemas. En este sentido a lo largo de este artículo se ha tratado de mostrar como von Wright y Apel llevaron a cabo una reconstrucción del tránsito que a lo largo de estos 50años se ha producido en las tendencias más recientes de la metodología científica post-analítica hacia la formulación de una nueva versión explicativo-comprensiva de aquellos anteriores modelos analítico-sintéticos. En cualquier caso se puede afirmar que esta doble versión del positivismo lógico hoy día se justifica en nombre de unos presupuestos crítico-transcendentales que en gran parte están en las antípodas de sus propuestas iniciales, aunque no cabe duda que les han permitido renacer de sus cenizas ${ }^{97}$.

95. Cf. Ortiz de Landázuri, C.; 'El error neurocientífico de Descartes, entre Spinoza y Tomás de Aquino. El debate entre Damasio y Stump sobre el materialismo eliminativo en la neuroética, neuropolítica y neuroeconomía'. Recerca y análisis, Valencia, 2016, pp.

96. Cf. Ortiz de Landázuri, C.; 'La persistencia del "tiempo", del "yo" y de los "mundos" epocales hegelianos después de Wittgenstein. A través de John McDowell', Falgueras, I.; García, J. A.; Padial, J. J. (eds.); Yo y tiempo. La antropología filosófica de G. W. F. Hegel. Vol I: La sustancialidad y subjetividad humanas, Contrastes, Suplemento 15, Málaga, 2010, 339-350.

97. Cf. Dorschel, A. (Hg.); Transzendentalpragmatik. Ein Symposion für Karl-Otto Apel, Suhrkamp, Frankfurt, 1993.

Thémata. Revista de Filosofía N55 (2017) pp.: 83-130. 
Carlos Ortiz de Landázuri

Thémata. Revista de Filosofía Nº5 (2017) pp.: 83-130. 